\title{
Straightforward conversion of decoquinate into inexpensive tractable new derivatives with significant antimalarial activities
}

\author{
Richard M. Beteck ${ }^{\mathrm{a}}$, Dina Coertzen ${ }^{\mathrm{b}}$, Frans J. Smit ${ }^{\mathrm{c}}$, Lyn-Marie Birkholtz ${ }^{\mathrm{b}}$, Richard K. Haynes ${ }^{\mathrm{c}^{*}}$, \\ David D. N'Da ${ }^{\mathrm{c}^{*}}$
}

a Pharmaceutical Chemistry, School of Pharmacy, North-West University, Potchefstroom 2520, South Africa.

b Department of Biochemistry, Centre for Sustainable Malaria Control, University of Pretoria, Pretoria 0002, South Africa

c Centre of Excellence for Pharmaceutical Sciences, North-West University, Potchefstroom 2520, South Africa.

*Corresponding authors: richard.haynes@nwu.ac.za; Tel: +27 ; Fax: +27 18299 4243; david.nda@ @wu.ac.za; Tel: +27 18299 2256; Fax: +27 182994243.

Keywords: Malaria, quinolone, decoquinate, derivatives, antimalarial activity.

\begin{abstract}
As part of a programme aimed at identifying rational new triple drug combinations for treatment of malaria, tuberculosis and toxoplasmosis, we have selected quinolones as one component, given that selected examples exhibit exceptionally good activities against the causative pathogens of the foregoing diseases. The quinolone decoquinate (DQ), an old and inexpensive coccidiostat, displays anti-malarial activity in vitro against Plasmodium falciparum ( $P f$ ). However, because of its exceedingly poor solubility in water or organic solvents, development of DQ as a drug is problematical. We have therefore converted DQ in straightforward fashion into tractable new derivatives that display good activities in vitro against chloroquine-sensitive NF54 and multidrug-resistant K1 and W2 Pf, and relatively low toxicities against human fibroblast cells. The most active compound, the $\mathrm{N}$-acetyl derivative 30, is 5-fold more active than DQ against NF54 and K1 and equipotent with DQ against W2. It possesses an activity profile against all strains comparable with that of the artemisinin derivative artesunate. Overall, this compound and the other accessible and active derivatives serve as an attractive template for development of new and economic lead quinolones.
\end{abstract}

\section{Graphical Abstract}

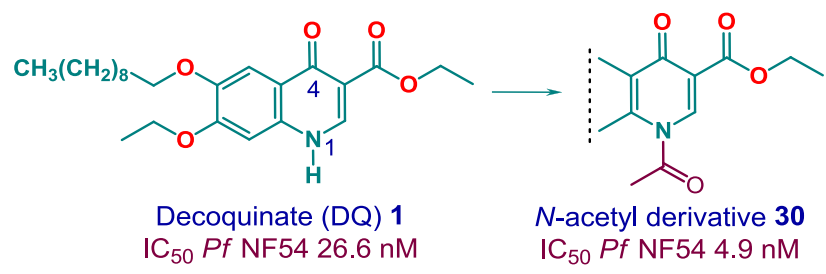


Under a programme designed to develop new triple drug combinations for the treatment of malaria, tuberculosis, and toxoplasmosis, ${ }^{1}$ we are preparing and evaluating efficacies of compound sets based on combinations of oxidant and redox drugs $^{2}$ coupled with a third partner with a different mode of action. In the case of malaria, the need to develop new drug combinations is particularly pressing. ${ }^{3}$ Chemotherapy coupled with vector control and inculcation of public awareness has reduced mortality due to malaria by over $66 \%$ since $2000 .^{4}$ However, the emergence of malaria parasites resistant to the current clinically-used artemisinin derivatives ${ }^{5}$ mandates the urgent development of newer artemisinin derivatives. Such derivatives must be incapable of providing the active metabolite dihydroartemisinin (DHA) common to the current clinical artemisinins, and should be rationally combined with the redox drug and a third combination partner to counter resistance and inhibit spread of resistant phenotypes by blocking transmission. ${ }^{6}$ The third partner is logically constructed about the $4(1 H)$ quinolone scaffold. In addition to being used clinically against a variety of infectious diseases including tuberculosis, ${ }^{7}$ certain quinolones have acquired lead status for development of drugs for treatment of toxoplasmosis ${ }^{8,9}$ and malaria ${ }^{10,11,12}$ respectively.

Our attention is drawn to decoquinate (DQ, 1) that has been used for many years in veterinary medicine largely coadministered with poultry feed for treatment of coccidiosis wherein it displays negligible toxicity. ${ }^{13,14}$ It is also used against other apicomplexan infections in animals ${ }^{15}$ and is highly active in a murine model against Toxoplasma gondii. ${ }^{16}$ Activity of DQ against malaria including $P$. berghei ${ }^{17}$ in mice and $P$. cynomolgi ${ }^{18}$ in monkeys has been known for some time. DQ is active $i n$ vitro against the liver, blood and gametocyte parasite stages of $P$. falciparum $(P f) .{ }^{19,20}$ Although such multistage activity matches the profile required for blocking transmission of the malaria parasite, 6 DQ like other $4(1 H)$-quinolones including the advanced lead compound ELQ $300,10^{12}$ is highly lipophilic with a $\log P$ of $8.19,{ }^{21}$ has exceedingly low solubility in water (0.06 $\left.\mathrm{mg} \mathrm{L}^{-1}\right) 14$ and other solvents, 12 and has low bioavailability. ${ }^{19,22}$ The decisive benefit of DQ is its low cost, $\leq \$ 10$ per kg, ${ }^{23}$ which renders it substantially cheaper than the other $4(1 H)$-quinolones proposed for further development as antimalarial drugs. However, the poor solubility markedly complicates screening both in vitro and in vivo and hampers evaluation of pharmacokinetic parameters, thereby restricting its further development as a drug. Because of this, resort has been made to preparation of nanoparticle formulations that appear to enhance efficacy against malaria in an animal model.22 Our approach consistent with the overall aims of our work is to convert DQ into accessible and more tractable derivatives that in the first instance are amenable to screening in vitro. We report here the preparation and preliminary in vitro antimalarial activity and cytotoxicity of such derivatives.

Chemistry. The proposed steps involve conversion of the ethyl ester into the less readily metabolized amide ${ }^{24}$ and replacement of H-1 largely by acyl, carbamoyl or sulfonyl groups, operations that should improve physicochemical properties associated with enhanced polarity (Scheme 1). $N$-alkyl derivatives are also prepared based on structure-activity considerations vis-à-vis the $N$-acyl and $N$-sulfonyl derivatives.

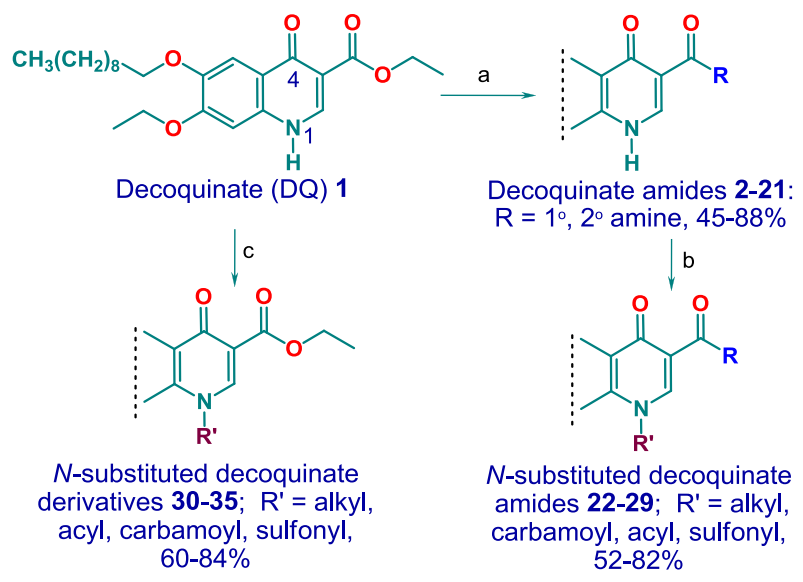

a. $1^{\circ}$ or $2^{\circ}$ amine (5 equiv.), DBU (0.9 equiv.), $\mathrm{CHCl}_{3}$, reflux $24-72 \mathrm{~h}$; b. DQ amide, alkyl, acyl or sulfonyl halide (5 equiv.), DBU (0.6 equiv.), $\mathrm{CHCl}$, reflux, $15 \mathrm{~h}$; c. DQ, as for b.

Scheme 1. Conversion of decoquinate (DQ) into DQ amide derivatives. 

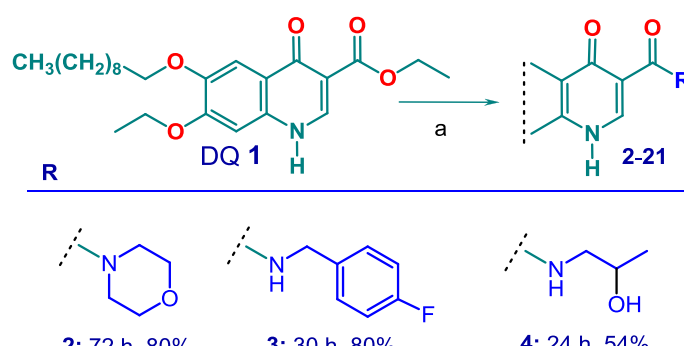

2: $72 \mathrm{~h}, 80 \% \quad$ 3: $30 \mathrm{~h}, 80 \% \quad 24 \mathrm{~h}, 54 \%$
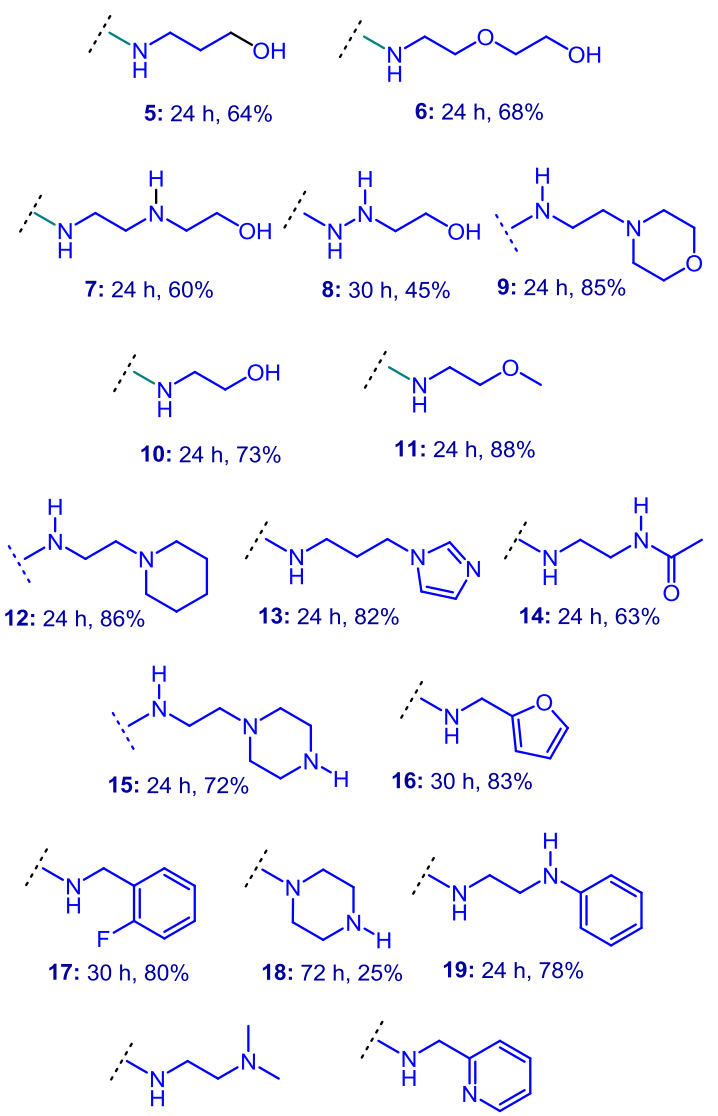

20: $24 \mathrm{~h}, 74 \% \quad 21: 30 \mathrm{~h}, 80 \%$

Figure 1. Amides obtained from direct aminolysis of decoquinate $\mathbf{1}$ with primary and secondary amines in chloroform according to method a, Scheme 1 ; reaction time $(\mathrm{h})$, overall yields given.

For the ester aminolysis (step a, Scheme 1), DQ is acidic with a pKa of 9.81,21 and thus a basic amine nucleophile under standard aminolysis conditions ${ }^{25}$ is likely to undergo competitive equilibrating proton transfer with $\mathrm{H}-1$ of the $4(1 H)$ quinolone ( $c f$. Figure 2 below). Whilst this problem may be countered by the use of Lewis acidic reagents, ${ }^{26}$ base-catalyzed aminolysis with an amine and 1,8-diazabicyclo[5.4.0]undec-7-ene (DBU) ${ }^{27}$ attracts because of its economy. Although the reactions may be conducted with the neat reactants and reagents, the most expeditious involved the heating of DQ and excess of primary or secondary amine with DBU in a solvent. We use chloroform here because of lack of solubility of DQ in other solvents, although it is emphasized that our initial concern is to obtain the new derivatives in the first place and then to optimize preparation for hit compounds using industrially acceptable solvents. Amides 2-21 (Fig 1) were obtained in good yields. Characterization data for the compounds are given in the Supplementary Material.

For functionalization at N-1 according to route b, Scheme 1, the decoquinate morpholino amide 2 was selected. Although the pKa of amide 2 with respect to deprotonation at $\mathrm{N}-1$ is unknown, it is likely this will be efficiently deprotonated by DBU in aprotic solvents to give the conjugate base $\mathbf{2}^{-}$that as an ambident anion may react through N-1 or O-4. In the event, the reactions with various acyl and sulfonyl chlorides, and alkyl halide proceeded smoothly through $\mathrm{N}-1$ to give the products 
22-29 in good yields (Figure 2). Whereas the IR spectrum of compound 2 shows an absorption at $3162 \mathrm{~cm}^{-1}$ due to the N-H stretching vibration in the quinolone nucleus, the peak is absent in derivatives 22-29, and a signal due to C-4 bearing an oxo group is evident at $c a .170 \mathrm{ppm}$ in the ${ }^{13} \mathrm{C}$ NMR spectra.

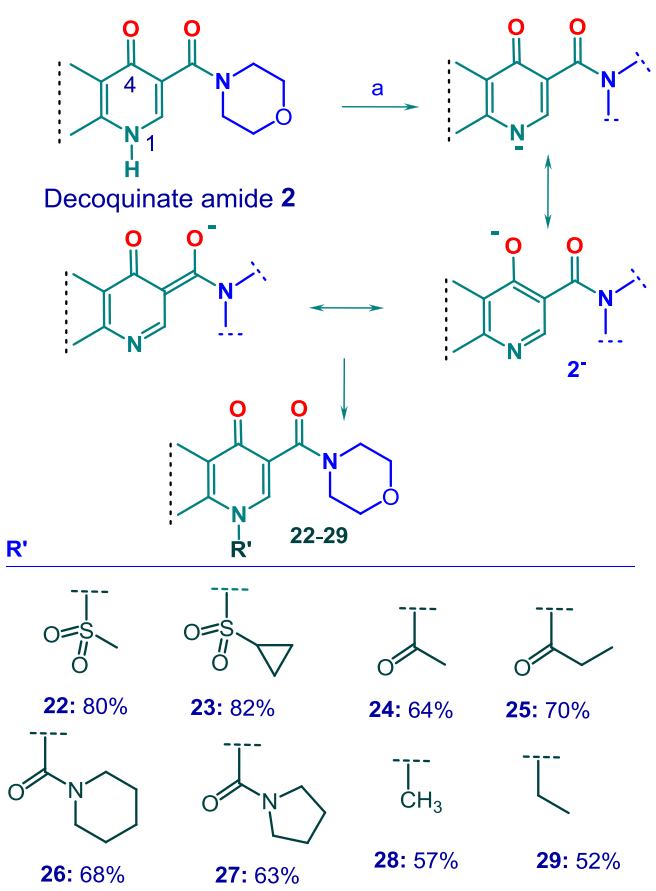

Figure 2. $N$-Substituted amide derivatives obtained from decoquinate amide 2 by treatment with DBU in the presence of sulfonyl, acyl and alkyl halides in chloroform with a reaction time of $15 \mathrm{~h}$ according to method $\mathrm{b}$, Scheme 1; overall yields given.

Decoquinate 1 was also functionalized at N-1 according to Scheme 1 route c to give the $N$-substituted decoquinate derivatives 30-35 in good yields (Figure 3). Data for derivatives 30, 31 and 33 appear in the Supplementary Material. As above, reaction through N-1 occurs in all cases. This is evident from the ${ }^{13} \mathrm{C}$ NMR spectra, which contain signals due to C-4 bearing an oxo group at ca. $170 \mathrm{ppm}$ and the ester carbonyl at 160-165 ppm.

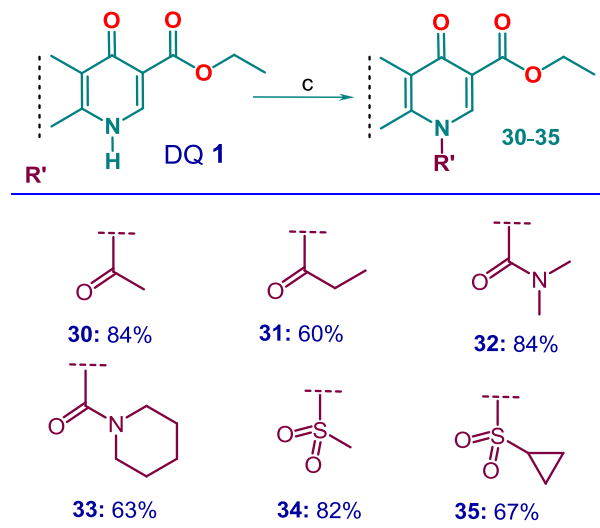

Figure 3. $\mathrm{N}$-Substituted decoquinate derivatives obtained from decoquinate $\mathbf{1}$ and DBU in the presence of acyl, carbamoyl, and sulfonyl chlorides in chloroform, with a reaction time of $15 \mathrm{~h}$ according to method c, Scheme 1; overall yields given.

In summary, decoquinate $\mathbf{1}$ is converted readily via aminolysis of the ethyl ester with primary and secondary amines in the presence of DBU in chloroform under reflux into the corresponding secondary and tertiary amides. Decoquinate $\mathbf{1}$ and the morpholino amide 2 under the foregoing conditions react with acyl and sulfonyl halides and alkyl halides through $\mathrm{N}-1$ to provide new $N$-substituted derivatives in good yields. 
Antimalarial activities: Decoquinate and the new derivatives were screened in vitro for antimalarial activity with the SYBR Green I-based fluorescence assay ${ }^{28}$ against Pf NF54 asexual blood stage parasites to determine the $\%$ inhibition of proliferation at initial compound concentrations of 1 and $5 \mu \mathrm{M}$ (Figure S1, Supplementary Material). Compounds showing the highest activity ( $>50 \%$ inhibition at $5 \mu \mathrm{M}$ and $>70 \%$ inhibition at $1 \mu \mathrm{M}$ ) were submitted to a second dual point assay at $100 \mathrm{nM}$ and $500 \mathrm{nM}$ (Figure S2, Supplementary Material). Compounds showing near complete inhibition of parasite proliferation were carried forward for $\mathrm{IC}_{50}$ determination against chloroquine (CQ)-sensitive Pf NF54 and multidrug resistant K1 and W2. CQ, the artemisinins artemether and artesunate, and decoquinate $\mathbf{1}$ were used as controls. Cytotoxicity of the compounds was also evaluated with the sulforhodamine B (SRB) assay on the WI-38 cell line ${ }^{29}$ using emetine as reference standard. $\mathrm{IC}_{50}$ values are summarized in Table 1. Of all compounds, only five, namely the decoquinate amides $\mathbf{3}$ and $\mathbf{6}$ (Fig. 1) and the N-substituted decoquinate derivatives 30, 31 and 33 (Fig. 3) showed near complete inhibition at 1 and $5 \mu \mathrm{M}$ regardless of the parasite strain (Fig. S2, Supplementary Material). Decoquinate $\mathbf{1}$ and the derivatives showed no appreciable toxicity to mammalian WI-38 cells; their $\mathrm{IC}_{50}$ values are all substantially greater than the $\mathrm{IC}_{50}$ of $0.05 \mu \mathrm{M}$ of emetine. The derivatives are thus selective in their antimalarial action as evidenced by the SI values $\geq 400$ (Table 1). The amides 3 and $\mathbf{6}$ (Fig. 1) are as active as DQ, but less active than both artemether and artesunate against all three parasite strains. The $N$-acyl derivative 30 (Fig. 3 ) on the other hand is equipotent with the two clinically used artemisinins against all strains, and is 5-fold more potent than DQ against $P f$ NF54 and K1, whilst being equipotent with DQ against W2. In general according to the resistance indices (Table 1), the other compounds are less active against K1 with respect to drug sensitive NF54, and essentially equipotent with DQ against W2. Although derivative $\mathbf{3 0}$ shows slight differences in activities between the three parasite strains, the selectivity indices indicate it is more selective than DQ in its antimalarial activity. Thus the balance between strain susceptibility, efficacy and safety favors derivative $\mathbf{3 0}$ over the parent decoquinate. It is to be noted that with the exception of compound $\mathbf{3}$, cLogP values indicate that all compounds are less lipophilic than decoquinate, and were able to be screened by preparing solutions in DMSO.

Table 1. Calculated LogP and in vitro biological data of selected derivatives.

\begin{tabular}{|c|c|c|c|c|c|c|c|c|}
\hline \multirow[t]{2}{*}{ Compound } & \multirow[t]{2}{*}{$\operatorname{cLog} \mathrm{P}^{\mathrm{a}}$} & \multicolumn{3}{|c|}{ Antimalarial activity $\mathrm{IC}_{50} \pm \mathrm{SEM}, \mathrm{nM}^{\mathrm{b}}$} & \multicolumn{2}{|c|}{$\begin{array}{c}\text { Resistance } \\
\text { Index }\end{array}$} & \multirow{2}{*}{$\begin{array}{c}\text { Cytotoxicity } \\
\mathrm{IC}_{50}, \mu \mathrm{M} \\
\mathrm{WI}-38^{\mathrm{e}}\end{array}$} & \multirow{2}{*}{$\begin{array}{c}\begin{array}{c}\text { Selectivity } \\
\text { Index }\end{array} \\
\mathrm{SI}^{\mathrm{f}}\end{array}$} \\
\hline & & NF54 & K1 & W2 & $\overline{\mathrm{RI}^{\mathrm{c}}}$ & $\mathrm{RI}^{\mathrm{d}}$ & & \\
\hline CQ & nd & $10 \pm 3$ & $154.73 \pm 14.96$ & $233.18 \pm 49.49$ & 15.4 & 23.3 & nd & nd \\
\hline Artemether & nd & $5.77 \pm 1.33$ & $7.26 \pm 2.34$ & $4.5 \pm 0.78$ & 1.3 & 0.8 & nd & nd \\
\hline Artesunate & nd & $7.88 \pm 1.35$ & $8.97 \pm 2.26$ & $6.77 \pm 1.13$ & 1.4 & 0.8 & $>100$ & $>12690$ \\
\hline DQ 1 & 8.2 & $26.6 \pm 1.4$ & $64.9 \pm 8.8$ & $15.4 \pm 3.4$ & 2.4 & 0.6 & $>100$ & $>3759$ \\
\hline 3 & 8.0 & $33.1 \pm 2.5$ & $63.1 \pm 9.8$ & $8.6 \pm 4.3$ & 1.9 & 0.2 & $>100$ & $>3021$ \\
\hline 6 & 6.0 & $40.4 \pm 1.3$ & $64.8 \pm 7.2$ & $18.5 \pm 4.5$ & 1.6 & 0.5 & 43.9 & 1087 \\
\hline 30 & 5.9 & $4.9 \pm 0.9$ & $12.0 \pm 3.5$ & $8.5 \pm 6.3$ & 2.5 & 1.7 & $>100$ & $>20408$ \\
\hline 31 & 6.5 & $15.4 \pm 0.5$ & $48.9 \pm 9.9$ & $11.5 \pm 1.2$ & 3.2 & 0.8 & $>100$ & $>6494$ \\
\hline 33 & 6.5 & $18.3 \pm 4.8$ & $89.1 \pm 6.0$ & $28.2 \pm 11.7$ & 4.9 & 1.5 & 8.5 & 465 \\
\hline Emetine & nd & nd & nd & nd & nd & nd & 0.05 & nd \\
\hline
\end{tabular}

${ }^{\mathrm{a}} \mathrm{cLogP}$ values calculated with ACD/ChemSketch Version 14.02; ${ }^{\mathrm{b}}$ data from at least three independent biological repeats, each performed in triplicate; $\mathrm{CQ}=$ chloroquine; $\mathrm{nd}=$ not determined; ${ }^{\mathrm{c}}$ resistance index $(\mathrm{RI})=\mathrm{IC}_{50} \mathrm{~K} 1 / \mathrm{IC}_{50} \mathrm{NF} 54$; ${ }^{\mathrm{d}}$ resistance index $(\mathrm{RI})=\mathrm{IC}_{50} \mathrm{~W} 2 / \mathrm{IC} 50 \mathrm{NF} 54$; ${ }^{\mathrm{W} I}-38$ cell line of normal human fetal lung fibroblast (HFLF); ${ }^{\mathrm{f}}$ selectivity index (SI) $=\mathrm{IC}_{50}$ WI-38-HFLF/IC ${ }_{50}$ NF54.

To conclude, the derivative $\mathbf{3 0}$ that has an in vitro activity profile comparable to that of artesunate coupled with a favorable incipient toxicity profile, and others of Table 1 represent easily accessible and economic hit compounds to guide the preparation of new and potent derivatives. As foreshadowed in the introduction, activities of these and related compounds against Mycobacterium tuberculosis and Toxoplasma gondii have also been recorded, and will be reported elsewhere.

\section{Acknowledgments}


This research project is funded by the South African Medical Research Council (MRC) with funds from the National Treasury under its Economic Competitiveness and Support Package. The South African National Research Foundation is thanked for financial support to LMB (UID 84627) and RKH (Grant No. 90682). Any opinion, finding and conclusion or recommendation expressed in this material is that of the author(s) and the NRF does not accept any liability in this regard. RMB, FS, RKH, and DDN also thank the North-West University for financial support. The authors express their gratitude to Natasha Kolesnikova, Molecular and Biomedical Technologies, CSIR Biosciences, Pretoria, South Africa, for performing the cytotoxicity screening.

\section{Supplementary Material}

Preparation of decoquinate derivatives, spectroscopic data for all derivatives; illustration of ${ }^{1} \mathrm{H},{ }^{13} \mathrm{C}-\mathrm{NMR}$ and mass spectra for derivatives $2,3, \mathbf{6}, 24,30,31,33$; details of in vitro malaria and cytotoxicity screening assays; Figs.S1, S2. 
1. $\quad$ see http://www.mrc.ac.za/strategic/flagship.htm, accessed 2 March 2016.

2. $\quad$ For definitions, see Haynes, R. K.; Cheu, K.-W.; Chan, H.-W.; Wong, H.-N.; Li, K. Y.; Tang, M. M.-K.; Chen, M.-J.; Guo, Z.-F.; Guo, Z.-H.; Sinniah, K.; Witte, A. B.; Coghi, P.; Monti, D. ChemMedChem. 2012, 7, 2204-2226; Haynes, R. K.; Cheu, K.-W.; N'Da, D. D.; Coghi, P.; Monti, D. Infectious Disorders - Drug Targets, 2013, 13, 217-277, p. 228.

3. Lotharius, J.; Gamo-Benito, F. J.; Angulo-Barturen, I.; Clark, J.; Connelly, M.; Ferrer-Bazaga, S.; Parkinson, T.; Viswanath, P.; Bandodkar, B.; Rautela, N.; Bharath, S.; Duffy, S.; Avery, V. M.; Möhrle, J. J.; Guy, R. K.; Wells, T. Malaria Journal 2014, 13, 143; doi: 10.1186/1475-2875$13-143$.

4. http://www.who.int/malaria/publications/world-malaria-report-2015/report/en/, accessed 2 March 2016

5. $\quad$ Lubell, Y.; Dondorp, A.; Guérin, P. J.; Drake, T.; Meek, S.; Ashley, E.; Day, N. P.; White, N. J.; White, L. J. Malaria Journal 2014, 13, 452; doi: $10.1186 / 1475-2875-13-452$.

6. $\quad$ Burrows, J. N.; van Huijsduijnen, R. H.; Möhrle, J. J.; Oeuvray, C.; Wells, T.N.C. Malaria Journal 2013, 12, 187; doi: 10.1186/1475-2875-12187

7. Andriole, V. T. Clinical Infectious Diseases 2005, 41, S113.

8. Doggett, J. S.; Nilsen, A.; Forquer I.; Wegmann, K. W.; Jones-Brando, L.; Yolken, R. H.; Bordón, C.; Charman, S. A.; Katneni, K.; Schultz, T.; Burrows, J. N.; Hinrichs, D. J.; Meunier, B.; Carruthers, V. B.; Riscoe. M. K. PNAS 2012, 109, 15936; doi: 10.1073/pnas.1208069109.

9. Neville, A. J.; Zach, S. J.; Wang, X.-F.; Larson, J. J.; Judge, A. K.; Davis, L. A.; Vennerstrom, J. L.; Davis, P. H. Antimicrob. Agents. Chemother. 2015, 59, 7161 .

10. $\quad$ Monastyrskyi, A.; Kyle, D. E.; Manetsch, R. Curr. Top. Med. Chem. 2014, 14, 1693.

11. Cross, R. M.; Flanigan, D. L.; Monastyrskyi, A.; La Crue, A. N.; Sáenz, F. E.; Maignan, J. R.; Mutka, T. S.; White, K. L.; Shackleford, D. M.; Bathurst, I.; Fronczek, F. R.; Wojtas, L.; Guida, W. C.; Charman, S. A.; Burrows, J. N.; Kyle, D. E.; Manetsch. R. J. Med. Chem. 2014, $57,8860$.

12. Miley, G. P.; Pou, S.; Winter, R.; Nilsen, A.; Li, Y.; Kelly, J. X.; Stickles, A. M.; Mather, M. W.; Forquer, I. P.; Pershing, A. M.; White, K.; Shackleford, D.; Saunders, J.; Chen. G.; Ting, L. M.; Kim, K.; Zakharov, L. N.; Donini, C.; Burrows, J. N.; Vaidya, A. B.; Charman, S. A.; Riscoe, M. K. Antimicrob. Agents Chemother. 2015, 55, 5555.

13. Taylor, M. A.; Bartram, D. J. J. Vet. Pharmacol. Therap. 2012, 35, 417.

14. Opinion of the scientific panel on additives and products or substances used in animal feed on a request from the commission on the coccidiostat DECCOX in accordance with article 9G of council directive 70/524/EEC. The EFSA Journal 2003, 17, 1-40; http://www.efsa.europa.eu/sites/default/files/scientific_output/files/main_documents/17.pdf; Scientific opinion on the modification of authorisation of Deccox® decoquinate as feed additive for chickens for fattening. EFSA Journal 2013, 11, 3370-3382; 10.2903/j.efsa.2013.3370.

15. Ellison, S. P. Decoquinate, 4-hydroxyquinolones and napthoquinones combined with levamisole, imidazothiazole, for the prevention and treatment of sarcocystosis and equine protozoal myeloencephalitis caused by Sarcocystis and Neospora and other apicomplexan protozoans, US 20140045885 A1; Publication date Feb 13, 2014; Filing date Aug 10, 2012.

16. Pfefferkorn, E. R.; Borotz, S. E.; Nothnagel, R. F. J. Parasitol., 1993, 79, 559-564.

17. Ryley, J. F; Peters, W. Ann. Trop. Med. Parasitol. 1970, 64, 209.

18. Puri, S. K.; Dutta, G. P. Trans. R. Soc. Trop. Med. Hyg. 1990, 84, 759.

19. Nam, T.-G.; McNamara, C. W.; Bopp, S.; Dharia, N. V.; Meister, S.; Bonamy, G. M. C.; Plouffe, D. M.; Kato, N.; McCormack, S.; Bursulaya, B.; Ke, H.; Vaidya, A. B.; Schultz, P. G.; Winzeler, E. A. ACS Chem. Biol. 2011, 6, 1214.

20. Da Cruz, F. P.; Martin, C.; Buchholz, K.; Lafuente-Monasterio, M. J.; Rodrigues, T.; Sönnichsen, B.; Moreira, R.; Gamo, F. J.; Marti, M.; Mota, M. M.; Hannus, M.; Prudêncio, M. J. Infect. Dis. 2012, 205, 1278.

21. https://www.ebi.ac.uk/chembldb/index.php/compound/inspect/CHEMBL416230; accessed 2 April 2016.

22. Wang, H. L., Li, Q.; Reyes, S.; Zhang, J.; Zeng, Q.; Zhang, P.; Xie, L.; Lee, P. J.; Roncal, N.; Melendez, V.; Hickman, M.; Kozar, M. P, Nanomed. Nanotech. Biol. Med. 2014, 10, 57.

23. Decoquinate Pure coccidiostat. http://www.alibaba.com/product-detail/anti-coccidia-only-chemical-coccidiostat-Decoquinate_767939400.html; accessed 2 March 2016.

24. Lemke, T. L. "Review of Organic Functional Groups: Introduction to Medicinal Organic Chemistry" Ch. 12 Functional Derivatives of Carboxylic Acids, pp. 59-62; Lippincott Williams \& Wilkins, 2003; Uetrecht, J. P.; Trager, W. "Drug Metabolism: Chemical and Enzymatic Aspects" Ch. 6, p. 120; CRC Press, 2007.

Carey, F. A.; Sundberg, R. J. "Advanced Organic Chemistry. Part A Structure and Mechanisms," Springer Verlag US, 2007; Ch. 7, pp. 659-662. Lipton, M. F.; Basha, A.; Weinreb, S. M. Org. Synth. 1979, 59, 49; Ranu, B. C.; Dutta, P. A. Synth. Commun.2003, 33, 297.

de Lima, E. C.; de Souza, C. C.; Soares, R. de O.; Vaz, B. G.; Eberlin, M. N.; Dias, A. G.; Costa, P. R. R. J. Braz. Chem. Soc. 2011, $22,2186$. Smilkstein, M. S.; Nongluk, K.; Jane, X.; Wilairat, P.; Riscoe, M. Antimicrob Agents Chemother. 2004, 48, 1803-1806; Johnson, J. D.; Dennull, R. A.; Gerena, L.; Lopez-Sanchez, M.; Roncal, N. E.; Waters, N. C. Antimicrob. Agents Chemother. 2007, 51, 1926; Verlinden, B. K. Niemand, J.; Snyman, J.; Sharma, S. K.; Beattie, R. J.; Woster, P. M.; Birkholtz, L. M. J. Med. Chem. 2011, 54, 6624.

29. Skehan, P. S.; Ritsa, S; Scudiero, D.; Monks, A.; McMahon, J.; Vistica, D.; Warren, J. T.; Bokesch, H.; Kenney, S.; Boyd, M. R. J. Natl. Cancer Inst. 1990, 82, 1107; Vichai, V.; Kirtikara, K. Nat. Protocol. 2006, 1, 1112. 


\section{Supporting Information}

\section{Experimental Section}

\section{General procedures}

The amines, acyl, sulfonyl, carbamoyl and alkyl halides in this study were purchased from either Sigma Aldrich or AKSci and were used as supplied. NMR spectra were obtained on a $600 \mathrm{MHz}$ Bruker Avance ${ }^{\mathrm{TM}}$ III spectrometer as solutions in deuterated solvents $\left(\mathrm{CDCl}_{3}\right.$, or DMSO- $\left.d_{6}\right)$. All chemical shifts $(\delta)$ are reported in parts per million (ppm) values. ${ }^{1} \mathrm{H}$ chemical shifts are reported downfield of tetramethylsilane (TMS), and were internally referenced to the residual proton in $\mathrm{CDCl}_{3}$ (7.26 ppm), or DMSO$d_{6}(2.50 \mathrm{ppm}) .{ }^{13} \mathrm{C}$ chemical shifts were internally referenced to resonances in $\mathrm{CDCl}_{3}$ ( $\delta 77.16 \mathrm{ppm})$, or DMSO-d6 ( $\delta 39.51 \mathrm{ppm})$. Peak multiplicities are abbreviated as follows: $s$ (singlet), $d$ (doublet), dd(doublet of doublet), $t$ (triplet), $q$ (quartet), $p$ (pentet), and $\mathrm{m}$ (multiplet). Coupling constant $(\mathcal{J}$ ) are reported in $\mathrm{Hz}$. NMR data were analyzed using MestReNova Software, version 5.3.2-4936. Exact mass measurements were recorded on Bruker MicroTOF Q II mass spectrometer with its APCl source set at $300{ }^{\circ} \mathrm{C}$ coupled with Bruker Compass Data analysis 4.0 software. A full scan, ranging between $50-1500 \mathrm{~m} / z$, was generated at a capillary voltage of $4500 \mathrm{~V}$, end plate offset voltage of $-500 \mathrm{~V}$, and a collision cell RF voltage of $100 \mathrm{~V}$. Infrared (IR) spectra were recorded on a Bruker Alpha-P FTIR instrument. Melting points $(\mathrm{mp})$ were determined with a Büchi melting point B-545 instrument and were uncorrected. Thin layer chromatography (TLC) was performed using silica gel plates $\left(60 \mathrm{~F}_{254}\right)($ Merck) and components were visualized by ultraviolet light $(254 \mathrm{~nm})$. Silica gel 230-400 (particle size 40-63 $\mu \mathrm{m}$ ) mesh was used for column chromatography. Calculated LogP (cLogP) values were generated using ACD/ChemSketch version 14.02. 


\section{Syntheses}

(a) To a $100 \mathrm{~mL}$ two neck flask containing decoquinate $1(1 \mathrm{~g}, 2.34 \mathrm{mmol})$ and DBU (320 $\mu \mathrm{L}, 0.33 \mathrm{~g}, 2.1 \mathrm{mmol}, 0.9$ eq.) in chloroform $(25 \mathrm{~mL}$ ) was added the primary or secondary amine (5 eq.). The resulting mixture was stirred under reflux for 24-72 h. Progress of the reactions was monitored by tlc. Upon completion, the reaction mixture was concentrated in vacuo. The concentrated residue was taken into chloroform $(20 \mathrm{~mL})$ and washed with distilled water $(4 \times 20 \mathrm{~mL})$. The organic layer was dried $\left(\mathrm{Na}_{2} \mathrm{SO}_{4}\right)$, filtered and the filtrate was evaporated to dryness to leave the crude product, which was subjected to flash column chromatography on silica gel. The product was eluted with a mixture of dichloromethane/methanol $(10: 1, \mathrm{v} / \mathrm{v})$. The product was recrystallized from ethyl acetate and air dried. The amide derivatives 2-21 were thereby obtained in good yields using this procedure. Data for derivatives 2, 3 and 6 are given below.

(b) To a $100 \mathrm{~mL}$ two neck flask containing DQ (0.5 g $1.22 \mathrm{mmol} .1 \mathrm{eq})$, DBU (100 $\mu \mathrm{L} 0.7 \mathrm{mmol}, 0.6$ eq.) in chloroform (15 mL) was added the appropriate acyl or sulfonyl halide, or alkyl halide (5 eq). The mixture was stirred under reflux for $15 \mathrm{~h}$, and then washed with aqueous saturated $\mathrm{NH}_{4} \mathrm{Cl}$ solution $(3 \times 20 \mathrm{~mL})$. The organic layer was dried $\left(\mathrm{Na}_{2} \mathrm{SO}_{4}\right)$, filtered and the filtrate was evaporated to dryness to leave the crude product, which was submitted flash column chromatography on silica gel. Elution with dichloromethane/methanol $(20: 1, \mathrm{v} / \mathrm{v})$ gave the product mixture, that was evaporated under reduced pressure to leave the crude product that was recrystallized from acetone and air dried overnight. The $\mathrm{N}$-substituted derivatives $\mathbf{3 0}$ 35 were obtained in $50-80 \%$ yields. Data for derivatives $\mathbf{3 0}, \mathbf{3 1}$ and $\mathbf{3 3}$ are given below. 
The foregoing procedure was applied to the morpholino amide $1(0.35 \mathrm{~g}, 0.8$ mmol, 1 eq.) to give the $\mathrm{N}$-substituted derivatives 22-29.

$\mathrm{DQ}$ and key derivatives in this study have the general structure below.

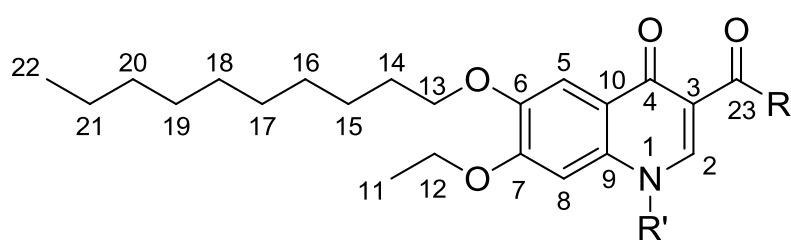

\begin{tabular}{|c|c|c|c|c|c|}
\hline Compd & $\mathbf{R}$ & $\mathbf{R}^{\prime}$ & Compd & $\mathbf{R}$ & $\mathbf{R}^{\prime}$ \\
\hline DQ 1 & & $\mathrm{H}$ & 24 & & \\
\hline 2 & & $\mathrm{H}$ & 30 & & \\
\hline 3 & & $\mathrm{H}$ & 31 & 24 & \\
\hline 6 & & $\mathrm{H}$ & 33 & & \\
\hline
\end{tabular}

\section{6-Decoxy-7-ethoxy-3-(morpholin-4-ylcarbonyl)quinolin-4(1H)-one 2}

White powder; yield: $80 \%$, 0.87 g; m.p.: $182-184{ }^{\circ} \mathrm{C}$; HPLC: $30 \%$ ACN $/ 70 \%$ 0.1\% $\mathrm{H}_{3} \mathrm{PO}_{4}$ gradient, $>93 \%$ pure, $\mathrm{rt}=5 \mathrm{~min} ; \operatorname{APCl}-\mathrm{HRMS}(\mathrm{m} / \mathrm{z}): 459.2793[\mathrm{M}+\mathrm{H}]^{+}$

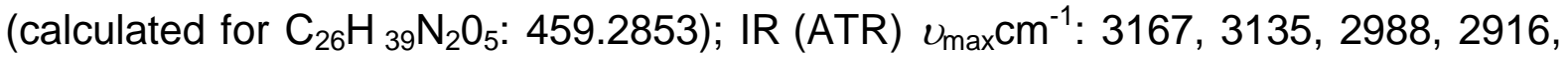
1633, 1604, 1566, 1539, 1000-574; ${ }^{1} \mathrm{H}$ NMR $\left(600 \mathrm{MHz}, \mathrm{CDCl}_{3}\right) \delta(\mathrm{ppm}): 11.96$ (s, $1 \mathrm{H}, \mathrm{H}-1), 7.67$ (s, 1H, H-2), $7.52(\mathrm{~s}, 1 \mathrm{H}, \mathrm{H}-5), 6.70(\mathrm{~s}, 1 \mathrm{H}, \mathrm{H}-8), 4.01-3.92(\mathrm{~m}, 4 \mathrm{H}$, $\mathrm{H}-12, \mathrm{H}-13), 3.76-3.68\left(\mathrm{~m}, 8 \mathrm{H}, \mathrm{H}-2^{\prime},-\mathrm{H}_{-} 5^{\prime}\right), 1.81(\mathrm{~m}, \mathrm{~J}=7.0 \mathrm{~Hz}, 2 \mathrm{H}, \mathrm{H}-14), 1.45-$ 
$1.35(\mathrm{~m}, 4 \mathrm{H}, \mathrm{H}-15, \mathrm{H}-16), 1.37-1.18(\mathrm{~m}, 13 \mathrm{H}, \mathrm{H}-11, \mathrm{H}-17,-\mathrm{H}-21), 0.85$ (t, J = 6.9 $\mathrm{Hz}, 3 \mathrm{H}, \mathrm{H}-22) ;{ }^{13} \mathrm{C}$ NMR (151 MHz, $\left.\mathrm{CDCl}_{3}\right) \delta(\mathrm{ppm}): 172.75$ (C-4), 167.79 (C-23), 153.61 (C-6), 147.80 (C-7), 138.63 (C-2), 135.00 (C-9), 120.22 (C-10), 115.47 (C-3), 105.57 (C-5), 99.84 (C-8), 69.17 (C-13) , 67.23 (C-3', C-4') , 64.61 (C-12), 48.08 (C2', C-5'), 31.88 (C-14), 29.54 (C-15, C-16), 29.35 (C-17, C-18), 28.97 (C-19), 25.93 (C-20), 22.66 (C-21), 14.45 (C-11), 14.10 (C-22).

\section{6-Decoxy-7-ethoxy-N-(4-fluorobenzyl)-4-oxo-1,4-dihydroquinoline-3-}

\section{carboxamide 3}

White powder; yield: $80 \%$, 0.82 g; m.p.: $202-203{ }^{\circ} \mathrm{C}$; HPLC: $30 \%$ ACN/ $70 \% 0.1 \%$ $\mathrm{H}_{3} \mathrm{PO}_{4}$ gradient, $>92 \%$ pure, $\mathrm{rt}=16.5 \mathrm{~min} ; \mathrm{APCl}-\mathrm{HRMS}(\mathrm{m} / \mathrm{z}): 497.2734[\mathrm{M}+\mathrm{H}]^{+}$ (calculated for $\mathrm{C}_{29} \mathrm{H}_{38} \mathrm{FN}_{2} \mathrm{O}_{4}: 497.2810$ ); IR (ATR) $v_{\max } \mathrm{cm}^{-1}: 3167,3135,2988,2916$, 1648, 1627, 1614, 1580, 1531,1498; ${ }^{1} \mathrm{H}$ NMR (600 MHz, $\left.\mathrm{CDCl}_{3}\right) \delta(\mathrm{ppm}): 11.85$ (s, $1 \mathrm{H}, \mathrm{H}-1), 11.11\left(\mathrm{t}, J=5.8 \mathrm{~Hz}, 1 \mathrm{H}, \mathrm{H}-1^{\prime}\right), 8.67(\mathrm{~s}, 1 \mathrm{H}, \mathrm{H}-2), 7.67(\mathrm{~s}, 1 \mathrm{H}, \mathrm{H}-5), 7.28$ (dd, $J=8.4,5.3 \mathrm{~Hz}, 2 \mathrm{H}, \mathrm{H}-5$ ', H-7'), 6.94 (t, J=8.5 Hz, 2H, H-4', H-8'), 6.81 (s, 1H, H-8), 4.66 (d, J = 5.8 Hz, 2H, H-2'), 4.05 (t, J=6.9 Hz, 2H, H-13), 3.92 (t, J=6.9 Hz, $2 \mathrm{H}, \mathrm{H}-12), 1.84$ (q, J = 7.4, $6.7 \mathrm{~Hz}, 4 \mathrm{H}, \mathrm{H}-14,-15), 1.47-1.18$ (m, 15H, H-11, H-16,$\mathrm{H}-21,), 0.92-0.82(\mathrm{~m}, 3 \mathrm{H}, \mathrm{H}-22) ;{ }^{13} \mathrm{C} \mathrm{NMR}\left(151 \mathrm{MHz}, \mathrm{CDCl}_{3}\right) \delta(\mathrm{ppm}): 176.11$ (C4), 166.87 (C-23), 162.83 (C-6'), 153.82 (C-6,) , 148.18 (C-7), 141.18 (C-2), 134.77 (C-9), 133.94 (C-3'), 128.93 (C-4', C-8'), 120.70 (C-10), 115.51 (C-5', C-7'), 110.05 (C-3), 105.92 (C-5), 99.85 (C-8), 69.26 (C-13), 64.70 (C-12) , 42.72 (C-2'), 31.87 (C14), 29.53 (C-15, C-16), 29.31 (C-17, C-18), 28.85 (C-19), 25.90 (C-20) , 22.66 (C21), $14.38(\mathrm{C}-11), 14.10(\mathrm{C}-22)$. 
6-Decoxy-7-ethoxy-N-[2-(2-hydroxyethoxy)ethyl]-4-oxo-1,4-dihydroquinoline-3carboxamide 6

White powder; yield: $68 \%$, 0.68 g; m.p.: $133-136{ }^{\circ} \mathrm{C}$; HPLC: $30 \%$ ACN/ $70 \% 0.1 \%$ $\mathrm{H}_{3} \mathrm{PO}_{4}$ gradient, > 96\% pure, $\mathrm{rt}=8.7 \mathrm{~min}$; APCl-HRMS $(\mathrm{m} / \mathrm{z}): 477.2911[\mathrm{M}+\mathrm{H}]^{+}$ (calculated for $\mathrm{C}_{26} \mathrm{H}_{41} \mathrm{~N}_{2} \mathrm{O}_{6}: 477.2959$ ); IR (ATR) $v_{\max } \mathrm{cm}^{-1}: 3336,3178,3135,3085$, 2922, 2849, 1639, 1581, 1561, 1523, 1499; ${ }^{1} \mathrm{H}$ NMR (600 MHz, $\left.\mathrm{CDCl}_{3}\right) \delta(\mathrm{ppm})$ : 11.99 (s, 1H, H-1), 10.73 (t, J = 5.3 Hz, 1H, H-1'), 8.64 (s, 1H, H-2), 7.39 (s, 1H, H5), $6.80(\mathrm{~s}, 1 \mathrm{H}, \mathrm{H}-8), 4.43\left(\mathrm{~s}, 1 \mathrm{H}, \mathrm{H}-7^{\prime}\right), 4.01$ (t, J = $\left.7.0 \mathrm{~Hz}, 2 \mathrm{H}, \mathrm{H}-13\right), 3.86$ (t, J = 6.8 $\mathrm{Hz}, 2 \mathrm{H}, \mathrm{H}-12), 3.83-3.78$ (m, 2H, H-2'), $3.71-3.60$ (m, 6H, H-3', H-5', H-6'), 1.76 (t, $J=6.9 \mathrm{~Hz}, 2 \mathrm{H}, \mathrm{H}-14), 1.46-1.19(\mathrm{~m}, 17 \mathrm{H}, \mathrm{H}-11, \mathrm{H}-15,-\mathrm{H}-21), 0.87$ (dt, $J=21.8,7.3$ $\mathrm{Hz}, 3 \mathrm{H}, \mathrm{H}-22) ;{ }^{13} \mathrm{C}$ NMR (151 MHz, $\left.\mathrm{CDCl}_{3}\right) \delta(\mathrm{ppm}): 175.76$ (C-4), 166.62 (C-23), 153.66 (C-6), 147.86 (C-7), 141.49 (C-2), 134.73 (C-9), 120.40 (C-10), 110.13 (C-3), 105.39 (C-5), 99.88 (C-8), 72.38 (C-2'), 69.80 (C-6'), 68.54 (C-3', C-5'), 64.63 (C-13), 61.73 (C-12), 31.90 (C-14), 29.65 (C-15, C-16), 29.27 (C-17, C-18), 28.92 (C-19, C20), 22.67 (C-21), 14.44 (C-11), 14.10 (C-22).

\section{1-Acetyl-6-decoxy-7-ethoxy-3-(morpholin-4-ylcarbonyl) quinolin-4(1H)-one 24}

White powder; yield: 64\%, 0.24 g; m.p. $142-144^{\circ} \mathrm{C}$; HPLC: $30 \%$ ACN/ $70 \% 0.1 \%$ $\mathrm{H}_{3} \mathrm{PO}_{4}$ gradient, > 83\% pure, rt = $12.6 \mathrm{~min}$; APCI-HRMS $(\mathrm{m} / \mathrm{z}): 501.2895[\mathrm{M}+\mathrm{H}]^{+}$ (calculated for $\mathrm{C}_{28} \mathrm{H}_{41} \mathrm{~N}_{2} \mathrm{O}_{6}: 501.2959$ ); IR (ATR) $v_{\max } \mathrm{cm}^{-1}: 2988,2916,1633,1604$, 1566, 1539, 1000-574; ${ }^{1} \mathrm{H}$ NMR (600 MHz, $\left.\mathrm{CDCl}_{3}\right) \delta(\mathrm{ppm}): 8.57$ (s, $\left.1 \mathrm{H}, \mathrm{H}-2\right), 7.3$ (s, $1 \mathrm{H}, \mathrm{H}-5), 6.92(\mathrm{~s}, 1 \mathrm{H}, \mathrm{H}-8), 4.18-4.11(\mathrm{~m}, 2 \mathrm{H}, \mathrm{H}-13), 4.09-4.03(\mathrm{~m}, 2 \mathrm{H}, \mathrm{H}-12)$, $3.74-3.30\left(m, J=16.1 \mathrm{~Hz}, 8 \mathrm{H}, \mathrm{H}^{-} 2^{\prime},-\mathrm{H}^{-} 5^{\prime}\right), 2.43(\mathrm{~s}, 3 \mathrm{H}, \mathrm{H}-\mathrm{b}), 1.88-1.73(\mathrm{~m}, 2 \mathrm{H}$, $\mathrm{H}-14), 1.57-1.45(\mathrm{~m}, 4 \mathrm{H}, \mathrm{H}-15, \mathrm{H}-16), 1.43-1.37(\mathrm{~m}, 2 \mathrm{H}, \mathrm{H}-17), 1.33-1.17$ (m, 
$11 \mathrm{H}, \mathrm{H}-11, \mathrm{H}-18,-\mathrm{H}-21), 0.87$ (dt, $J=14.0,7.3 \mathrm{~Hz}, 3 \mathrm{H}, \mathrm{H}-22) ;{ }^{13} \mathrm{C}$ NMR $(151 \mathrm{MHz}$, $\left.\mathrm{CDCl}_{3}\right) \delta(\mathrm{ppm}): 172.83$ (C-4), 167.24 (C-a), 165.61 (C-23), 153.25 (C-6), 147.71 (C7), 144.17 (C-2), 140.83 (C-9), 134.49 (C-10), 120.37 (C-3), 107.01 (C-5), 99.63 (C8), 69.24 (C-13), 67.32 (C-12), 66.79 (C-3'), 64.83 (C-4'), 47.94 (C-2'), 42.85 (C-5'), 31.86 (C-14), 29.52 (C-15), 29.49 (C-16), 29.31 (C-17), 29.28 (C-18), 28.88 (C-19), 27.03 (C-b), 25.89 (C-20), 22.64 (C-21), 14.41 (C-11), 14.08 (C-22).

\section{Ethyl-1-acetyl-6-decoxy-7-ethoxy-4-oxo-1,4-dihydroquinoline-3-carboxylate 30}

White powder; yield: $84 \%$, 0.42 g; m.p.: $159-162{ }^{\circ} \mathrm{C}$; HPLC: $30 \%$ ACN $/ 70 \% 0.1 \%$ $\mathrm{H}_{3} \mathrm{PO}_{4}$ gradient, > 97\% pure, $\mathrm{rt}=8.2 \mathrm{~min}$; APCI-HRMS $(\mathrm{m} / \mathrm{z}): 460.2656[\mathrm{M}+\mathrm{H}]^{+}$ (calculated for $\mathrm{C}_{26} \mathrm{H}_{38} \mathrm{NO}_{6}$ : 460.2694); IR (ATR) $\mathrm{U}_{\max } \mathrm{cm}^{-1}:$ 2988, 2916, 1743, 1604, 1566, 1539, 1000-574; ${ }^{1} \mathrm{H}$ NMR (600 MHz, $\left.\mathrm{CDCl}_{3}\right) \delta$ (ppm): 9.15 (s, $\left.1 \mathrm{H}, \mathrm{H}-2\right), 7.41$ (s, 1H, H-5), $7.12(\mathrm{~s}, 1 \mathrm{H}, \mathrm{H}-8), 4.47-4.30(\mathrm{~m}, 2 \mathrm{H}, \mathrm{H}-24), 4.31-4.21(\mathrm{~m}, 2 \mathrm{H}, \mathrm{H}-13)$, $4.13-4.03(\mathrm{~m}, 2 \mathrm{H}, \mathrm{H}-12), 2.51$ (s, 3H, H-b), $1.88-1.73(\mathrm{~m}, 2 \mathrm{H}, \mathrm{H}-14), 1.57-1.45$ (m, 4H, H-15, H-16), 1.43 - 1.37 (m, 2H, H-17), 1.33 - 1.17 (m, 14H, H-11, H-18, 21, -25,), 0.87 (dt, $J=14.0,7.3 \mathrm{~Hz}, 3 \mathrm{H}, \mathrm{H}-22) ;{ }^{13} \mathrm{C} \mathrm{NMR}\left(151 \mathrm{MHz}, \mathrm{CDCl}_{3}\right) \delta$ (ppm):172.83 (C-4), 165.61 (C-23), 154.46 (C-a), 154.06 (C-6), 150.44 (C-7), 149.37 (C-2), 130.86 (C-9), 117.55 (C-10), 113.16 (C-3), 108.72 (C-5), 100.60 (C-8), 69.15 (C-13), 68.11 (C-12), 64.19 (C-24), 31.87 (C-14), 29.52 (C-15), 29.49 (C-16), 29.31 (C-17), 29.28 (C-18), 28.88 (C-19), 25.89 (C-20), 22.64 (C-21), 21.13 (C-b), 14.39 (C-25), 14.27 (C-11), 14.09 (C-22). 


\section{Ethyl-6-decoxy-7-ethoxy-4-oxo-1-propionyl-1,4-dihydroquinoline-3-carboxylate}

31

White powder; yield: $60 \%, 0.30$ g; m.p.: $160-162^{\circ} \mathrm{C}$; HPLC: $30 \%$ ACN, $70 \% 0.1 \%$ $\mathrm{H}_{3} \mathrm{PO}_{4}$ gradient, > 96\% pure, $\mathrm{rt}=9.3 \mathrm{~min} ; \mathrm{APCl}-\mathrm{HRMS}(\mathrm{m} / \mathrm{z}): 474.2806[\mathrm{M}+\mathrm{H}]^{+}$ (calculated for $\mathrm{C}_{27} \mathrm{H}_{40} \mathrm{NO}_{6}$ : 474.2850); IR (ATR) $\cup_{\max } \mathrm{cm}^{-1}: 2988,2916,1741,1604$, 1566, 1539, 1000-574; ${ }^{1} \mathrm{H}$ NMR (600 MHz, $\left.\mathrm{CDCl}_{3}\right) \delta$ (ppm): 9.15 (s, 1H, H-2), 7.41 (s, $1 \mathrm{H}, \mathrm{H}-5), 7.12(\mathrm{~s}, 1 \mathrm{H}, \mathrm{H}-8), 4.47-4.30$ (m, 2H, H-24), $4.31-4.21$ (m, 2H, H-13), $4.13-4.03(\mathrm{~m}, 2 \mathrm{H}, \mathrm{H}-12), 2.91-2.81(\mathrm{~m}, 2 \mathrm{H}, \mathrm{H}-\mathrm{b}), 1.88-1.73(\mathrm{~m}, 2 \mathrm{H}, \mathrm{H}-14), 1.57$ -1.45 (m, 4H, H-15, H-16), $1.43-1.37$ (m, 2H, H-17), $1.33-1.17$ (m, 17H, H-11, H18,-H-21, H-25, H-C), 0.87 (dt, $J=14.0,7.3 \mathrm{~Hz}, 3 \mathrm{H}, \mathrm{H}-22) ;{ }^{13} \mathrm{C}$ NMR (151 MHz, $\left.\mathrm{CDCl}_{3}\right) \delta(\mathrm{ppm}): 172.83$ (C-4), 165.61 (C-23), 154.40 (C-a), 154.06 (C-6), 150.44 (C7), 149.37 (C-2), 130.86 (C-9), 117.55 (C-10), 113.16 (C-3), 108.72 (C-5), 100.60 (C8), 69.15 (C-13), 68.11 (C-12), 64.19 (C-24), 38.68 (C-b), 31.87 (C-14), 29.52 (C15), 29.49 (C-16), 29.31 (C-17), 29.28 (C-18), 28.88 (C-19), 25.89 (C-20), 22.64 (C21), 14.39 (C-c), 14.25 (C-25), 14.11 (C-11), 14.09 (C-22).

Ethyl-6-decoxy-7-ethoxy-4-oxo-1-(piperidin-1-ylcarbonyl)-1,4-dihydroquinoline-

\section{3-carboxylate 33}

White powder; yield: $63.7 \%$, 0.32 g; m.p.: $170-172^{\circ}$ C; HPLC: $30 \%$ ACN/ $70 \% 0.1 \%$ $\mathrm{H}_{3} \mathrm{PO}_{4}$ gradient, > 96\% pure, $\mathrm{rt}=7.3 \mathrm{~min} ; \mathrm{APCl}-\mathrm{MS}(\mathrm{m} / \mathrm{z}): 529.3236[\mathrm{M}+\mathrm{H}]^{+}$ (calculated for $\mathrm{C}_{30} \mathrm{H}_{45} \mathrm{~N}_{2} \mathrm{O}_{6}: 529.3272$ ); IR (ATR) $v_{\max } \mathrm{cm}^{-1}: 2988,2916,1733,1604$, 1566, 1539, 1000-574; ${ }^{1} \mathrm{H}$ NMR (600 MHz, $\left.\mathrm{CDCl}_{3}\right) \delta$ (ppm): 9.15 (s, 1H, H-2), 7.42 (s, $1 \mathrm{H}, \mathrm{H}-5), 7.12$ (s, $1 \mathrm{H}, \mathrm{H}-8), 4.47-4.30$ (m, 2H, H-24), $4.31-4.21(\mathrm{~m}, 2 \mathrm{H}, \mathrm{H}-13)$, $4.13-4.03(\mathrm{~m}, 2 \mathrm{H}, \mathrm{H}-12), 2.71-2.01(\mathrm{~m}, 10 \mathrm{H}, \mathrm{H}-\mathrm{b},-\mathrm{H}-\mathrm{f}), 1.88-1.73(\mathrm{~m}, 2 \mathrm{H}, \mathrm{H}-$ 
14), $1.57-1.45(\mathrm{~m}, 4 \mathrm{H}, \mathrm{H}-15, \mathrm{H}-16), 1.43-1.37(\mathrm{~m}, 2 \mathrm{H}, \mathrm{H}-17), 1.33-1.17$ (m, $14 \mathrm{H}, \mathrm{H}-11, \mathrm{H}-18,-\mathrm{H}-21, \mathrm{H}-25), 0.87$ (dt, $J=14.0,7.3 \mathrm{~Hz}, 3 \mathrm{H}, \mathrm{H}-22$ ).; ${ }^{13} \mathrm{C}$ NMR (151 $\left.\mathrm{MHz}, \mathrm{CDCl}_{3}\right) \delta(\mathrm{ppm}): 172.83$ (C-4), 165.61 (C-23), 154.48 (C-a), 154.06 (C-6), 150.44 (C-7), 149.37 (C-2), 130.86 (C-9), 117.55 (C-10), 113.16 (C-3), 108.72 (C-5), 100.60 (C-8), 69.15 (C-13), 68.11 (C-12), 64.19 (C-24), 54.58 (C-b, C-f), 31.89 (C-c, C-e), 31.87 (C-14), 29.57 (C-d'), 29.52 (C-15), 29.49 (C-16), 29.31 (C-17), 29.28 (C18), 28.88 (C-19), 25.89 (C-20), 22.64 (C-21), 14.25 (C-25), 14.11 (C-11), 14.09 (C22).

\section{In vitro antimalarial assays}

P. falciparum parasites were maintained at $37{ }^{\circ} \mathrm{C}$ in human erythrocytes $\left(\mathrm{O}^{+}\right)$ suspended in complete culture medium [RPMI 1640 medium (Sigma-Aldrich) supplemented with 25 mM HEPES (Sigma-Aldrich), 20 mM D-glucose (SigmaAldrich), $200 \mu \mathrm{M}$ hypoxanthine (Sigma-Aldrich), 0.2\% sodium bicarbonate, $24 \mu \mathrm{g} / \mathrm{mL}$ Gentamycin (Sigma-Aldrich) and 0.5\% AlbuMAX II] in a gaseous environment of $90 \% \mathrm{~N}_{2}, 5 \% \mathrm{O}_{2}$, and $5 \% \mathrm{CO}_{2} .{ }^{1}$ In vitro ring-stage intra-erythrocytic $P$. falciparum parasite cultures (Genotyped drug sensitive strains; W2 (Chloroquine, quinine, pyrimethamine and cycloguanil resistant), K1 (chloroquine, pyrimethamine, mefloquine and cycloguanil resistant) and NF54 (drug sensitive) (200 $\mu \mathrm{L}$ at 1\% haematocrit, $1 \%$ parasitaemia) were treated with the DQ derivatives series.

The controls for this assay included chloroquine disulphate $(1 \mu \mathrm{M}$, as positive control) and complete RPMI media (as negative control) and grown for $96 \mathrm{~h}$ at $37^{\circ} \mathrm{C}$ under the $90 \% \mathrm{~N}_{2}, 5 \% \mathrm{O}_{2}$, and $5 \% \mathrm{CO}_{2}$ gas mixture in 96 -well plates.

At the end of the $96 \mathrm{~h}$ growth period, equal volumes (100 $\mu \mathrm{L}$ each) of the $P$. falciparum parasite cultures were combined with SYBR Green I lysis buffer $(0.2$ $\mu \mathrm{L} / \mathrm{mL} 10000$ x SYBR Green I, Invitrogen; 20 mM Tris, pH 7.5; 5 mM EDTA; 0.008\% (w/v) saponin; 0.08\% (v/v) Triton X-100).

The samples were incubated at $37^{\circ} \mathrm{C}$ for $1 \mathrm{~h}$ after which the fluorescence was measured using a Fluoroskan Ascent FL microplate fluorometer (Thermo Scientific, excitation at $485 \mathrm{~nm}$ and emission at $538 \mathrm{~nm}$ ). The 'background' fluorescence (i.e. that measured in the samples derived from chloroquine-treated $\mathrm{RBC}$ samples in 
which parasite proliferation was completely inhibited) was subtracted from the total fluorescence measured for each sample to provide a measure of parasite proliferation.

Data obtained were analysed in Excel 2010 and sigmoidal dose-response curves were plotted using GraphPad 6.0.

Decoquinate 1 and the derivatives were screened at $5 \mu \mathrm{M}$ and $1 \mu \mathrm{M}$ against the NF54 strain of asexual $P$. falciparum parasites to determine their \% inhibition. Compounds showing near complete inhibition at $5 \mu \mathrm{M}$ and $1 \mu \mathrm{M}$ (Figure S1), were further screened at 500 and $100 \mathrm{nM}$ against NF54 parasites (Figure S2). Compounds were weighed $(1 \mathrm{mg})$ and dissolved in $100 \%$ DMSO and made up to a $10 \mathrm{mM}$ stock and stored at $-20^{\circ} \mathrm{C}$. Some compounds, however, did not completely dissolve $\left(2,8,12,14,22,31,32,33,34\right.$ and 35) despite being incubated at $37^{\circ} \mathrm{C}$ for $>1 \mathrm{~h}$. These were dissolved at lower stock concentrations $(<5 \mathrm{mM})$ and treated with $1 \mathrm{xPBS}$. Therefore, prior to assay these compounds were vortexed thoroughly and the suspensions were immediately used to make up the working solutions in complete RMPI-1640 media.

Solutions/suspensions of compounds were thawed at room temperature $(\sim 1$ h) prior to an assay to prepare working solutions. The final starting concentrations ( 5 , $1 \mu \mathrm{M}$ and 500, $100 \mathrm{nM}$ ) were prepared in complete RPMI-1640 media and aliquoted in triplicate into a 96-well plate. The \%DMSO in the starting concentration was $0.05 \%$ for the $5 \mu \mathrm{M}, 0.000125 \%$ for the $1 \mu \mathrm{M}, 0.05 \%$ for the $500 \mathrm{nM}$ and $0.00000125 \%$ for the $100 \mathrm{nM}$ drug concentrations; these concentrations were below the parasite inhibition threshold as previously determined in our laboratory. Following dual point assays, compounds were subjected to in vitro $\mathrm{IC}_{50}$ determinations against asexual $P$. falciparum NF54, $\mathrm{K} 1$ and $\mathrm{W} 2$ parasites. The respective $\mathrm{IC}_{50}$ values for compounds in the series showing activity $<100 \mathrm{nM}$ were determined (DQ $\mathbf{1}$ and compounds 3, 6, 30, 31, 33). The same methods and conditions were applied for dissolving and storing the compounds as described for the dual point assays. Fresh stock solutions of the compound used for the $\mathrm{IC}_{50}$ determinations were prepared prior to assays and stored at $-20{ }^{\circ} \mathrm{C}$. All assays were performed in triplicate for at least three independent biological repeats. 


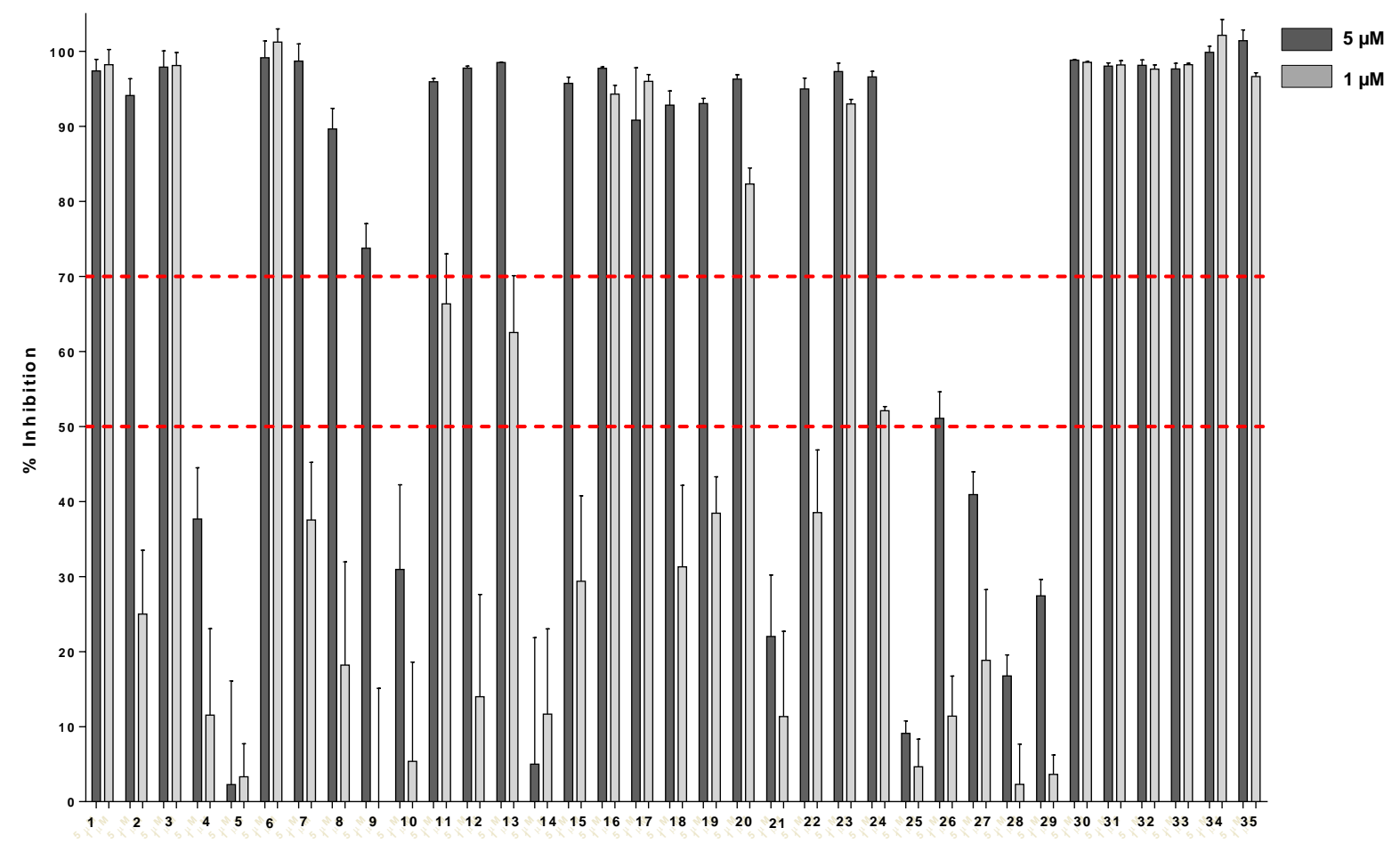

Figure S1: Inhibitory potential against asexual NF54 $P$. falciparum parasites. Compounds were incubated at $5 \mu \mathrm{M}$ and $1 \mu \mathrm{M}$ against asexual NF54 P. falciparum parasites. Several compounds showed near complete inhibition of parasite proliferation as determined with the SYBR Green I fluorescence based assay following incubation at $37^{\circ} \mathrm{C}$ for $96 \mathrm{~h}$ with decoquinate 1 as control. Data analysis were performed in triplicate for $\mathrm{n}=3$ independent biological repeats with GraphPad 6.0 ; the average \% inhibition is shown and error bars indicate SEM. 


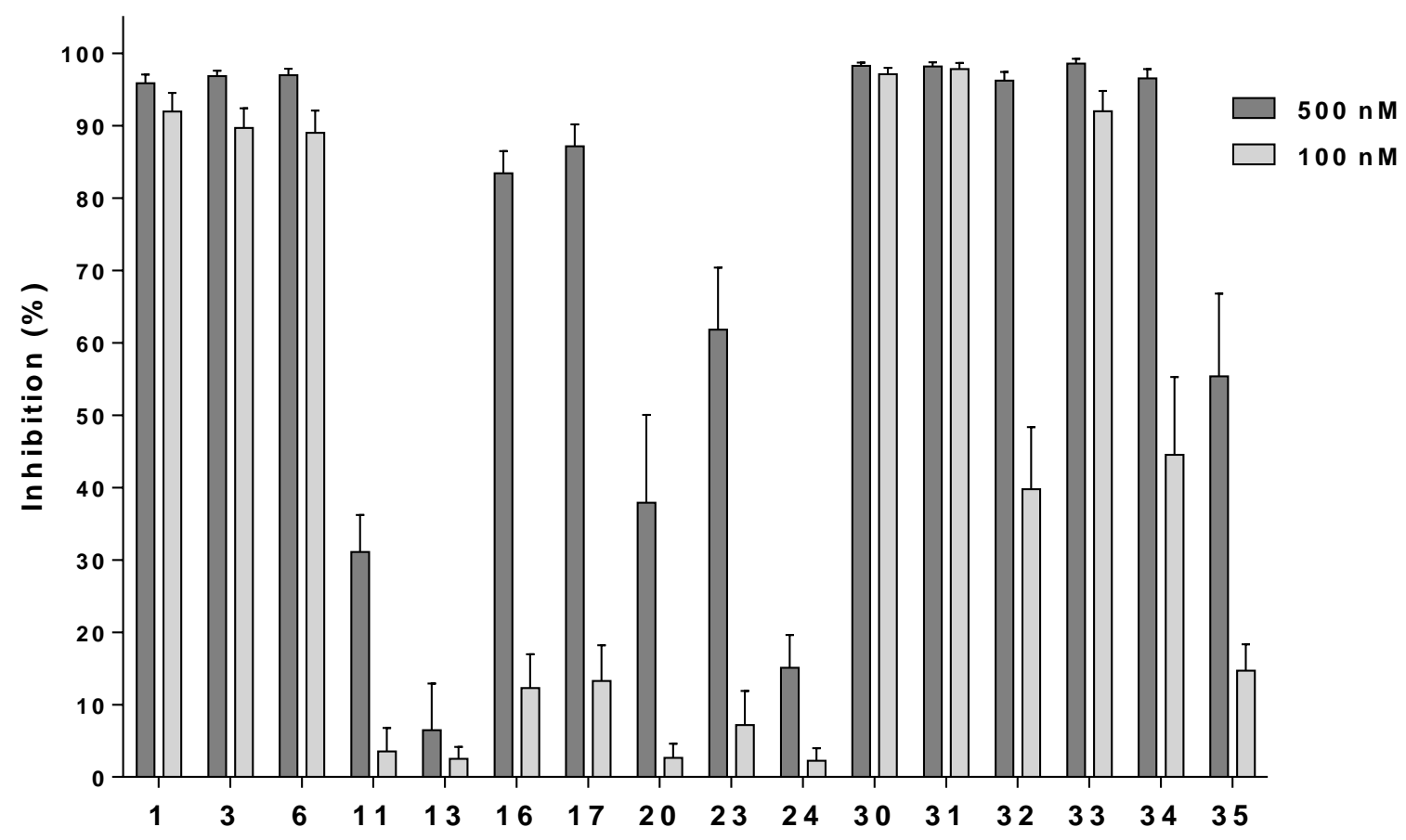

Figure S2: Inhibitory potential against asexual NF54 $\boldsymbol{P}$. falciparum parasites.

The most active compounds at $5 \mu \mathrm{M}$ and $1 \mu \mathrm{M}$ were incubated at $500 \mathrm{nM}$ and 100 nM against asexual NF54 P. falciparum parasites. Eight compounds showed near complete inhibition of parasite proliferation as determined with the SYBR Green I fluorescence based assay following incubation at $37^{\circ} \mathrm{C}$ for $96 \mathrm{~h}$. Data analysis were performed in triplicate for $n=3$ independent biological repeats with GraphPad 6.0; the average \% inhibition is shown and error bars indicate SEM.

\section{In vitro cytotoxicity}

The WI-38 cell line (normal human fetal lung fibroblast) from ECACC was maintained as a monolayer cell culture at $37{ }^{\circ} \mathrm{C}, 5 \% \mathrm{CO}_{2}, 95 \%$ air and $100 \%$ relative humidity in EMEM containing $10 \%$ fetal bovine serum, $2 \mathrm{mM} \mathrm{L}$-glutamine and $50 \mu \mathrm{g} / \mathrm{mL}$ gentamicin. For this screening experiment, the cells (21 - 50 passages) were inoculated in 96-well microtiter plates at plating densities of 10000 cells/well and incubated for 24 hours. After 24 hours, the cells were treated with the experimental drugs; which had previously been dissolved in DMSO and diluted in medium to produce five concentrations. Neat cells served as the control. The blank contained complete medium without cells. Parthenolide was used as a standard. The plates were incubated for 48 hours after addition of the compounds. Viable cells were fixed 
to the bottom of each well with cold $50 \%$ trichloroacetic acid, washed, dried and dyed by SRB. Unbound dye was removed and protein bound dye was extracted with 10 $\mathrm{mM}$ Tris base for optical density determination at a wavelength of $540 \mathrm{~nm}$ using a multiwell spectrophotometer. Data analysis was performed using GraphPad Prism software. $50 \%$ of cell growth inhibition $\left(\mathrm{IC}_{50}\right)$ was determined by non-linear regression. 


\section{NMR and HRMS spectra of key derivatives}

\section{Compound 2}

\section{${ }^{1}$ H NMR spectrum}

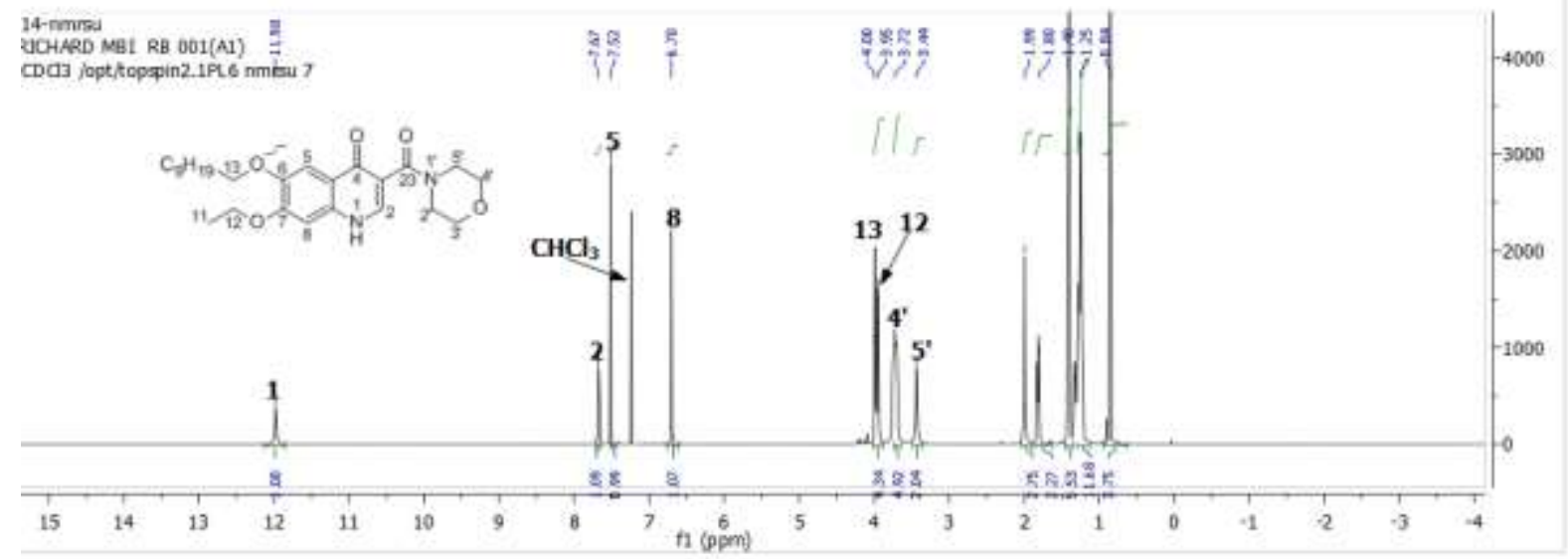

\section{${ }^{13}$ C NMR spectrum}

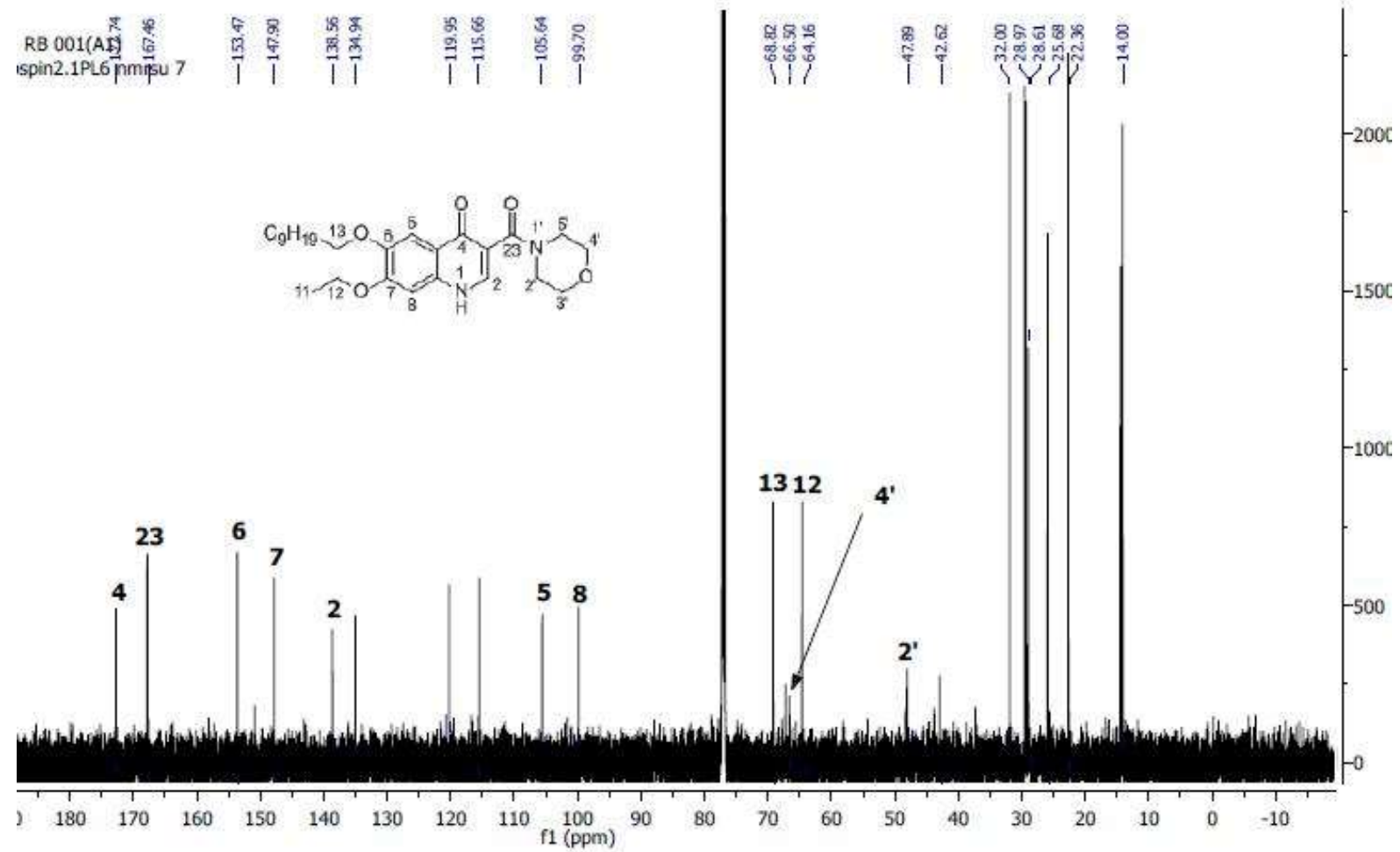




\section{HRMS spectrum}

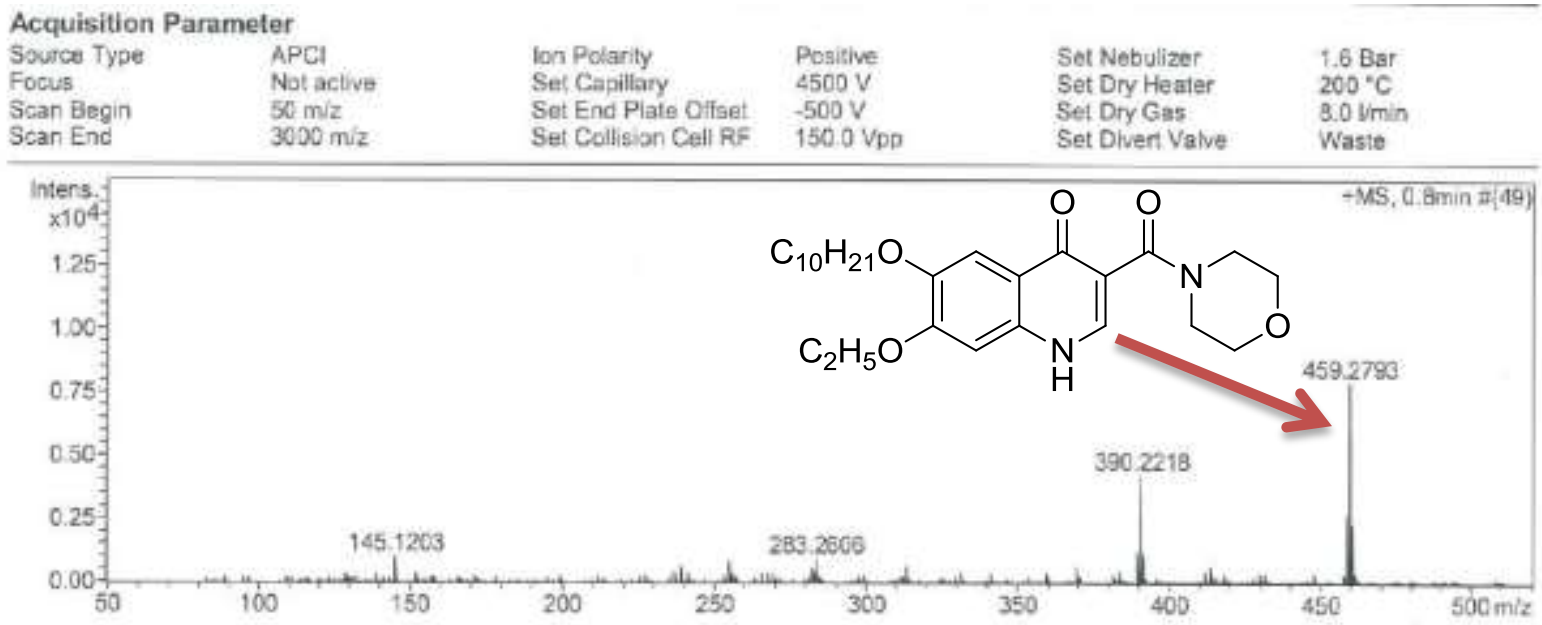




\section{Compound 3}

\section{${ }^{1}$ H NMR spectrum}
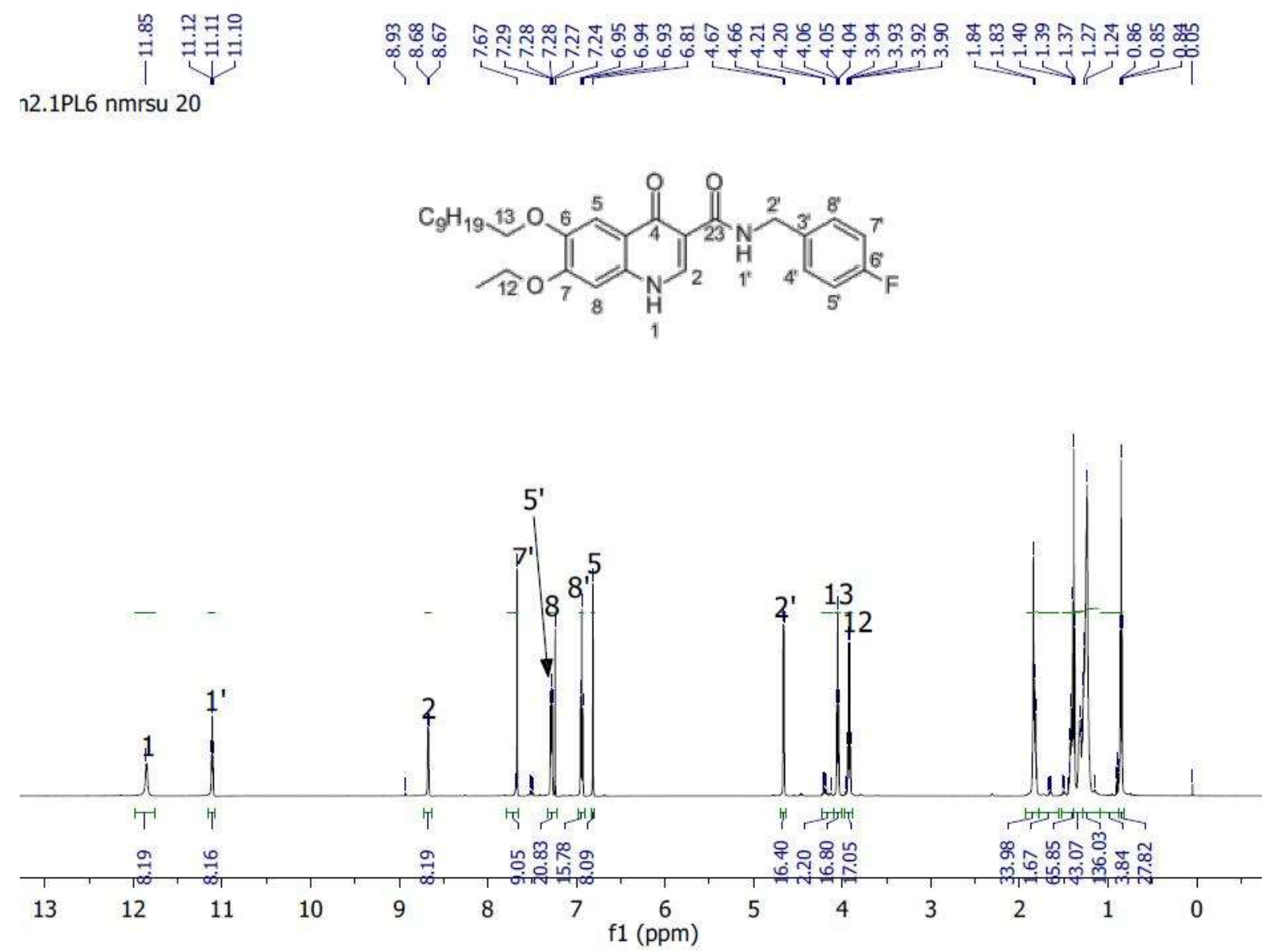


\section{${ }^{13} \mathrm{C}$ NMR spectrum}

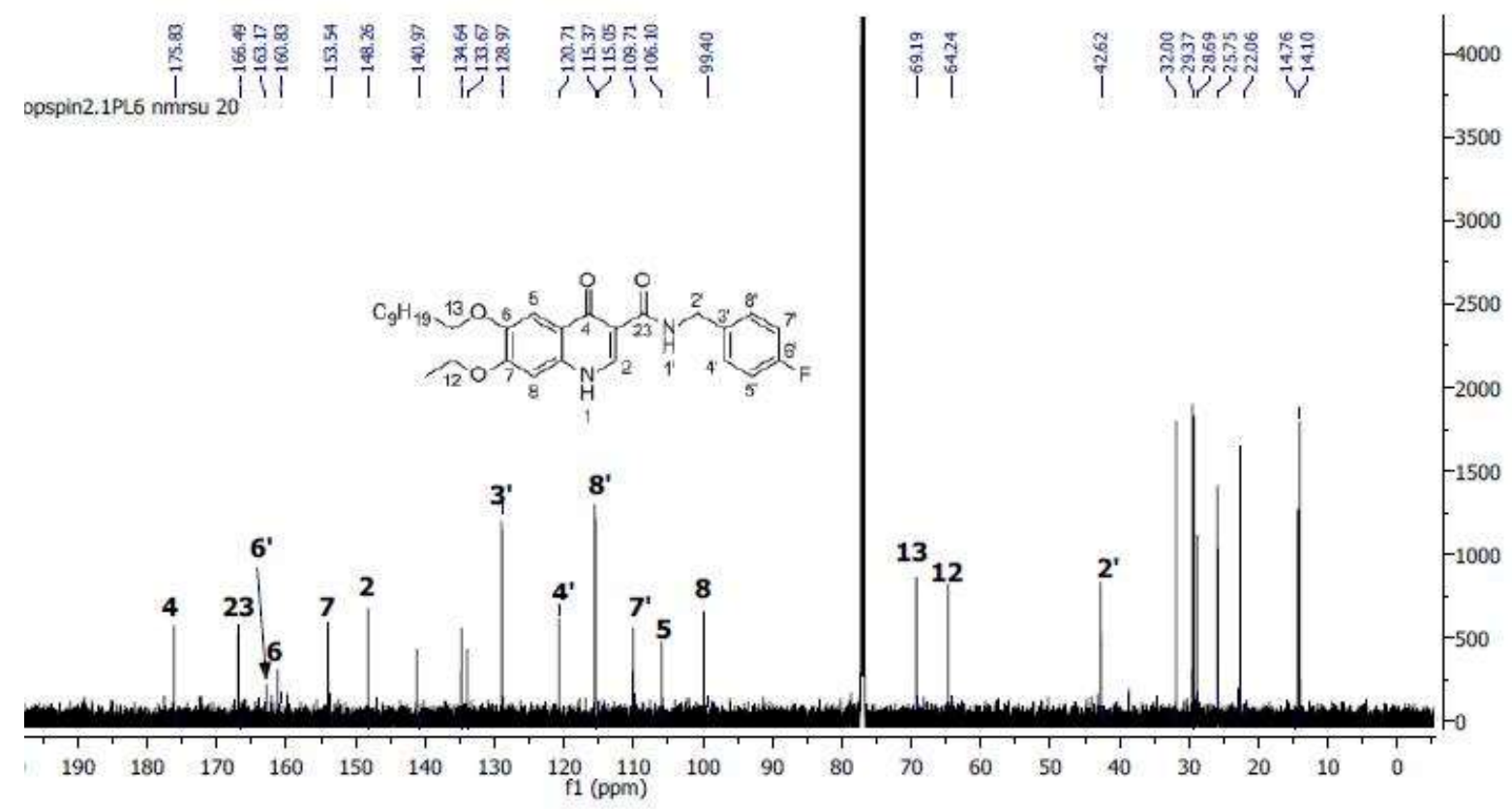

HRMS Spectrum

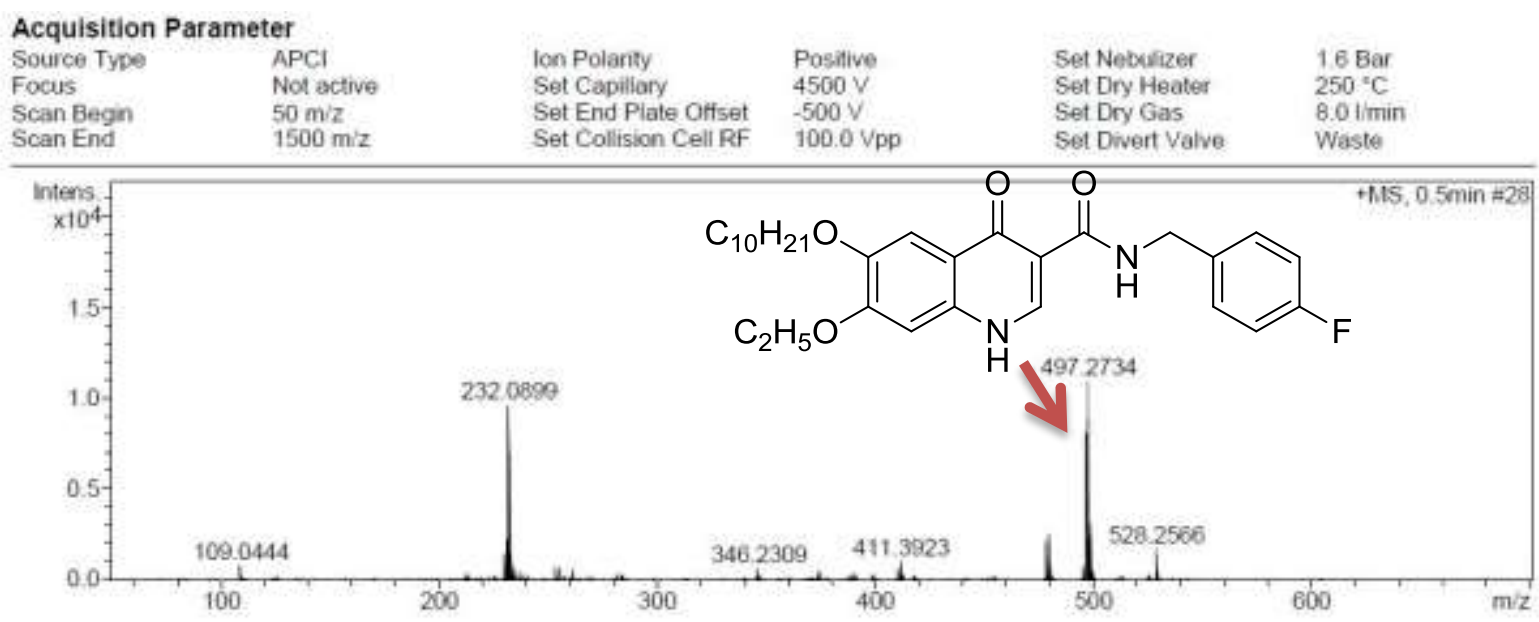


Compound 6

\section{${ }^{1}$ H NMR spectrum}

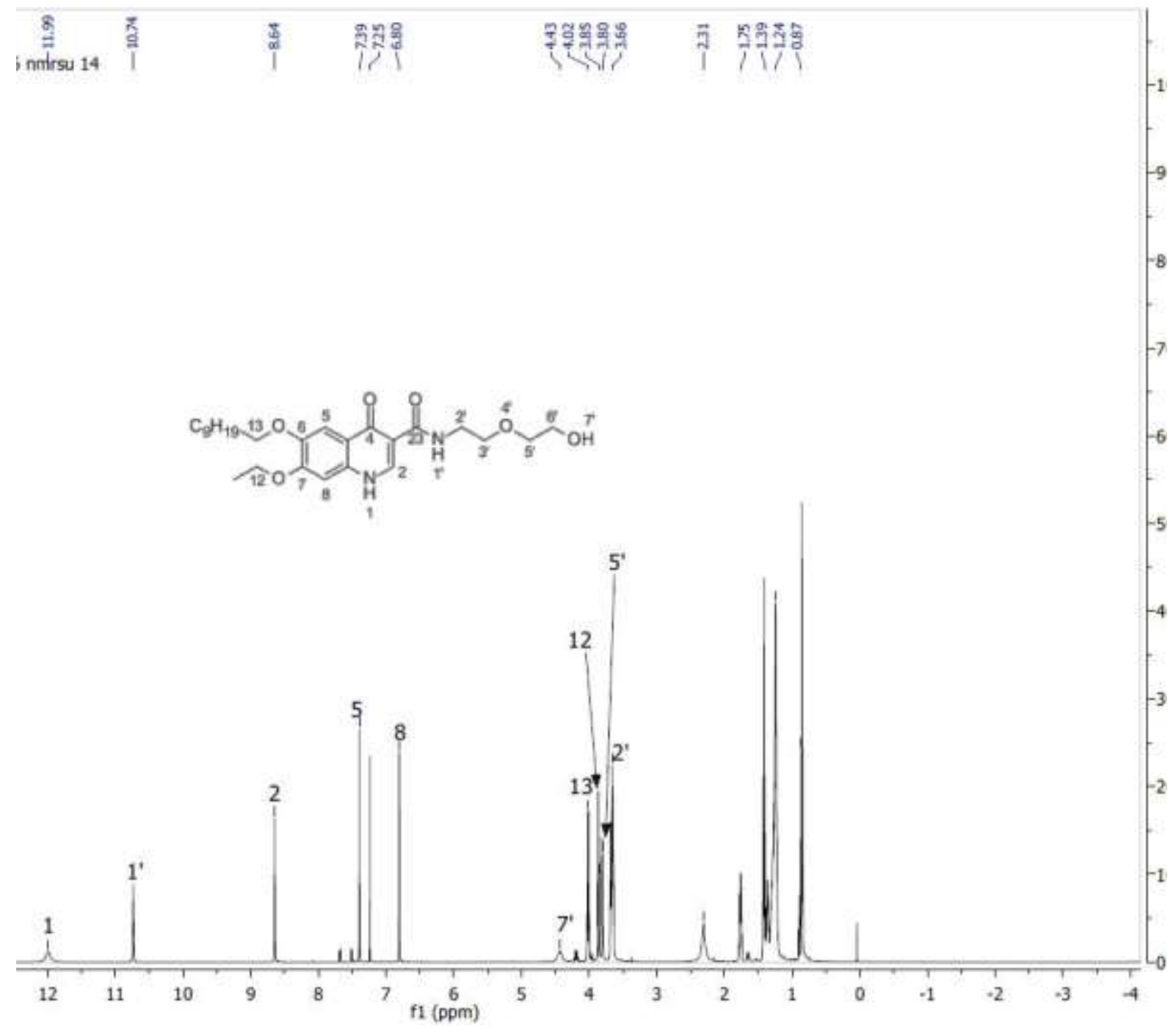




\section{${ }^{13}$ C NMR spectrum}

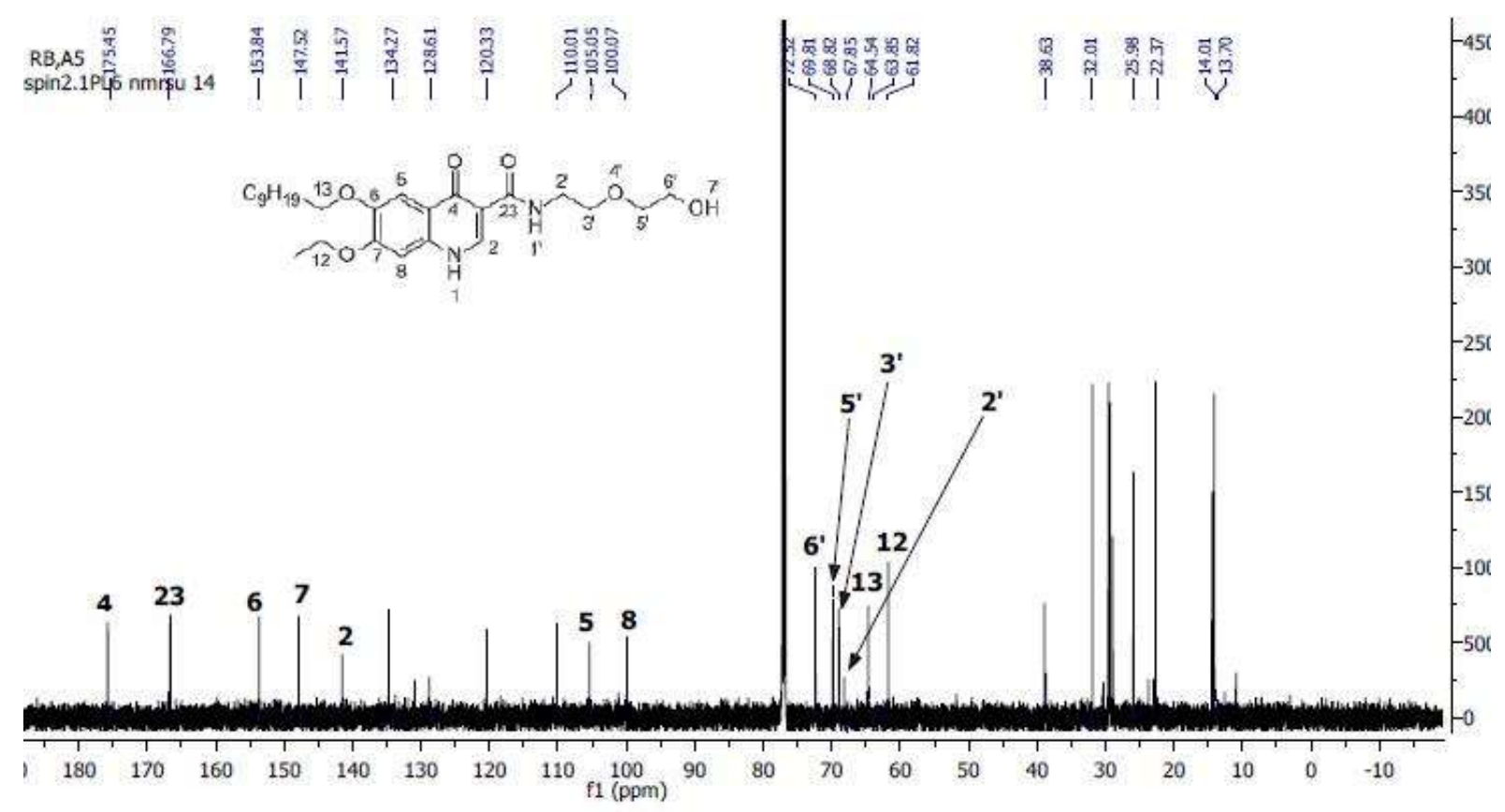

HRMS spectrum

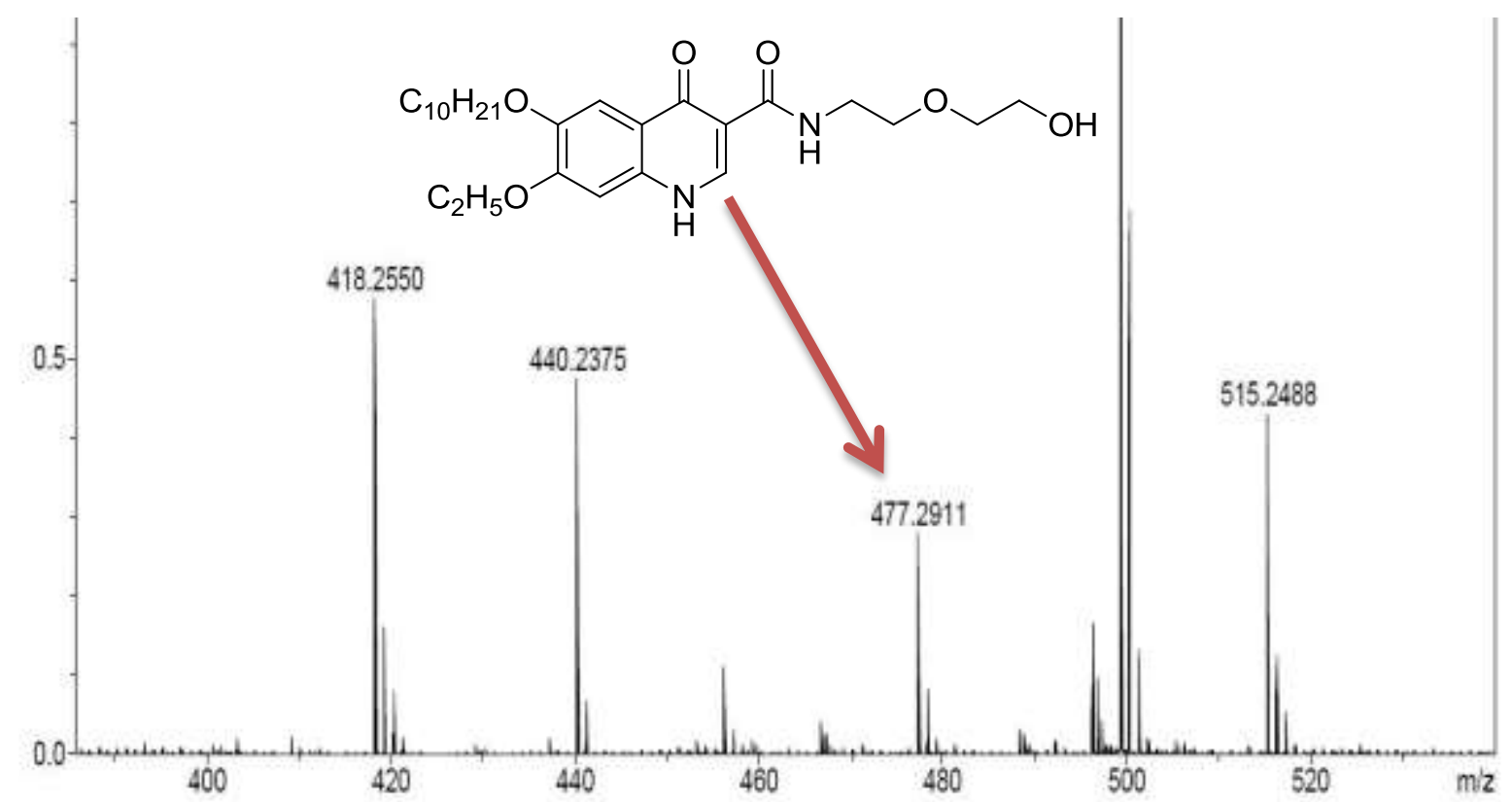

uker Compass DataAnalysis 4.0 


\section{Compound 24}

\section{${ }^{1}$ H NMR spectrum}

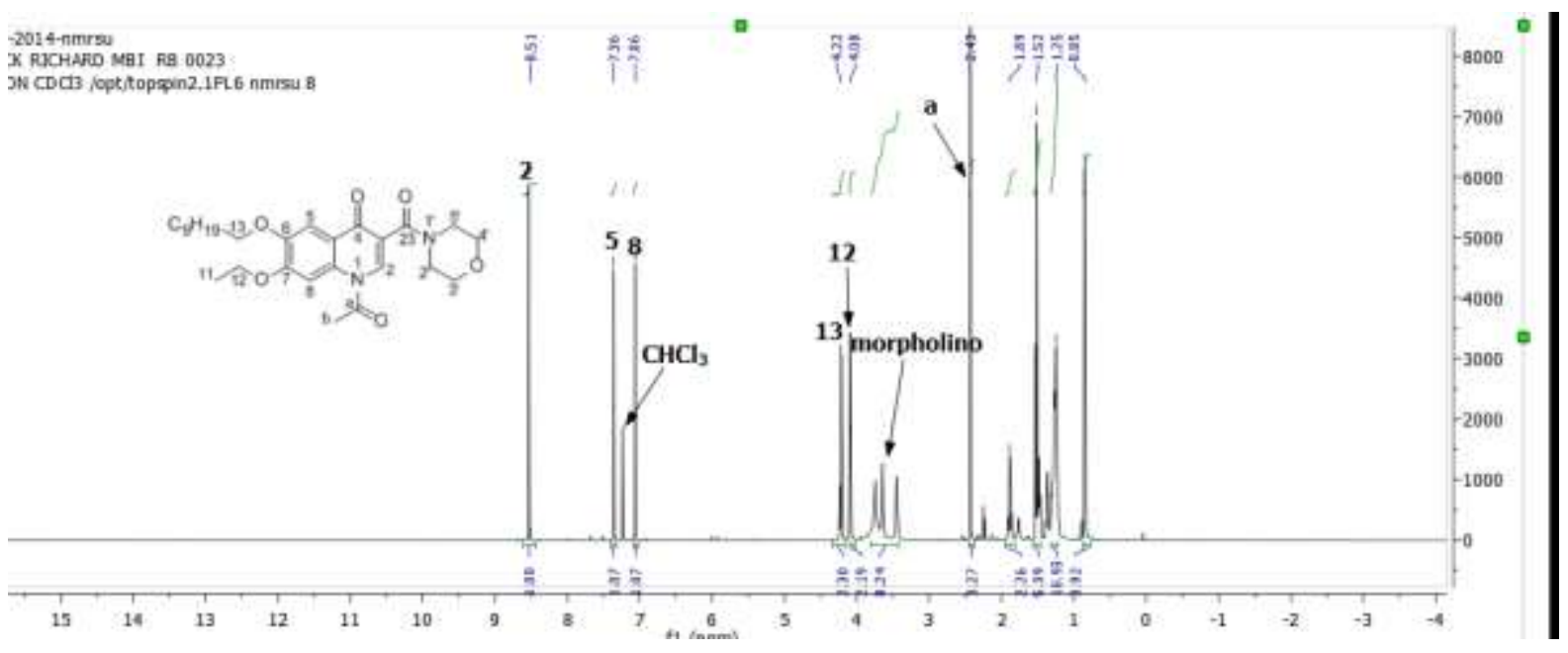

${ }^{13}$ C NMR spectrum

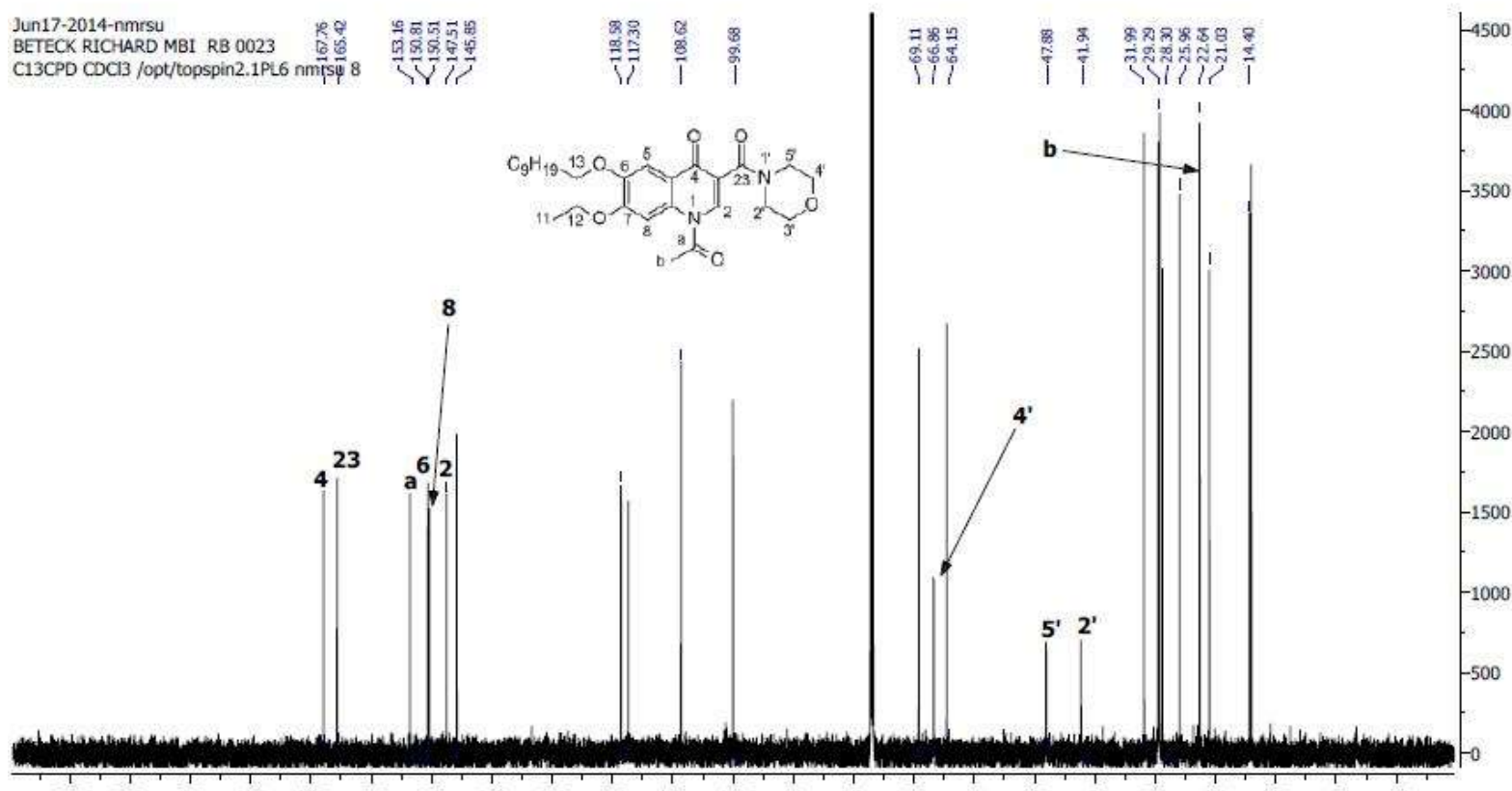

$\begin{array}{lllllllllllllllllllllll}210 & 200 & 190 & 180 & 170 & 160 & 150 & 140 & 130 & 120 & 110 & \begin{array}{l}100 \\ \mathrm{f} 1(\mathrm{ppm})\end{array} & 90 & 80 & 70 & 60 & 50 & 40 & 30 & 20 & 10 & 0 & -10\end{array}$

HRMS spectrum 


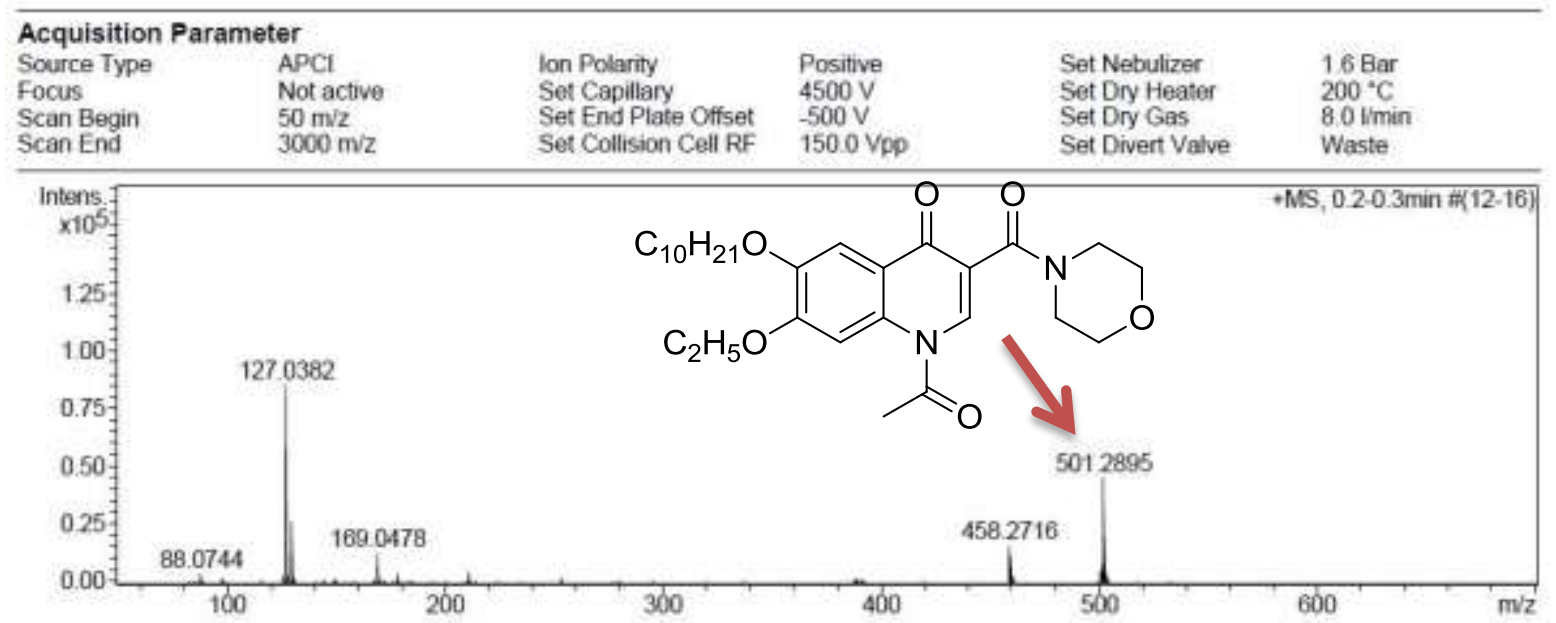

Compound 30

\section{${ }^{1}$ H NMR spectrum}

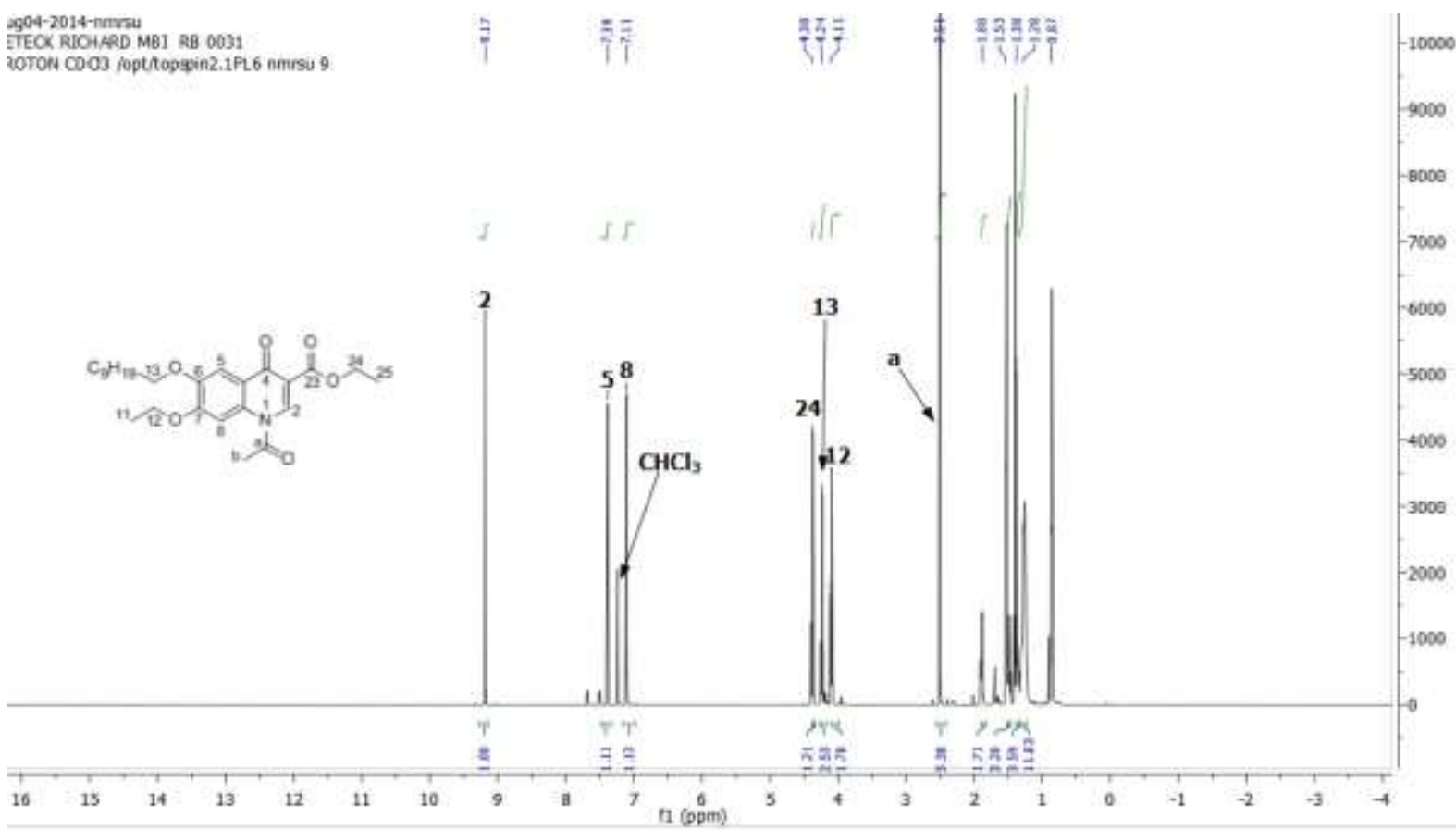




\section{${ }^{13} \mathrm{C}$ NMR spectrum}

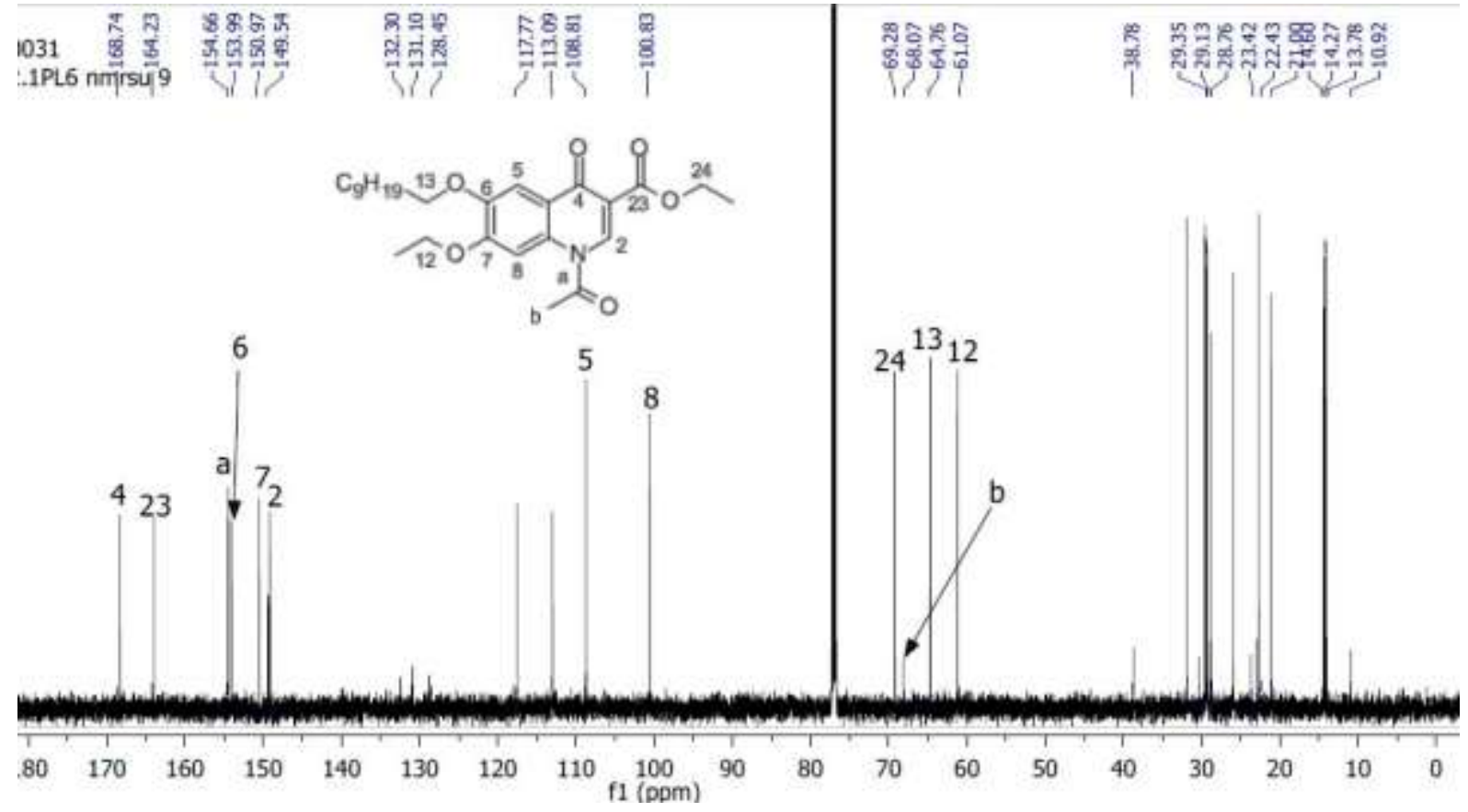

HRMS spectrum

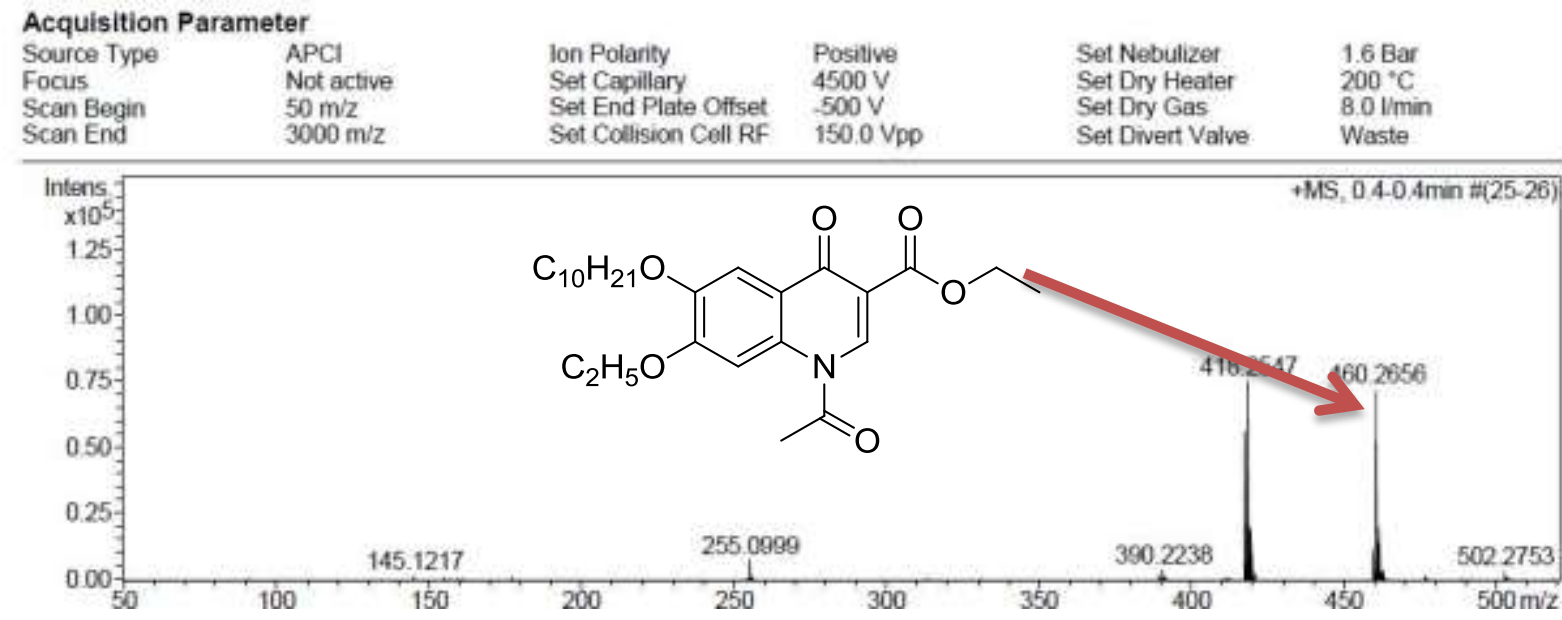




\section{Compound 31}

\section{${ }^{1}$ H NMR spectrum}

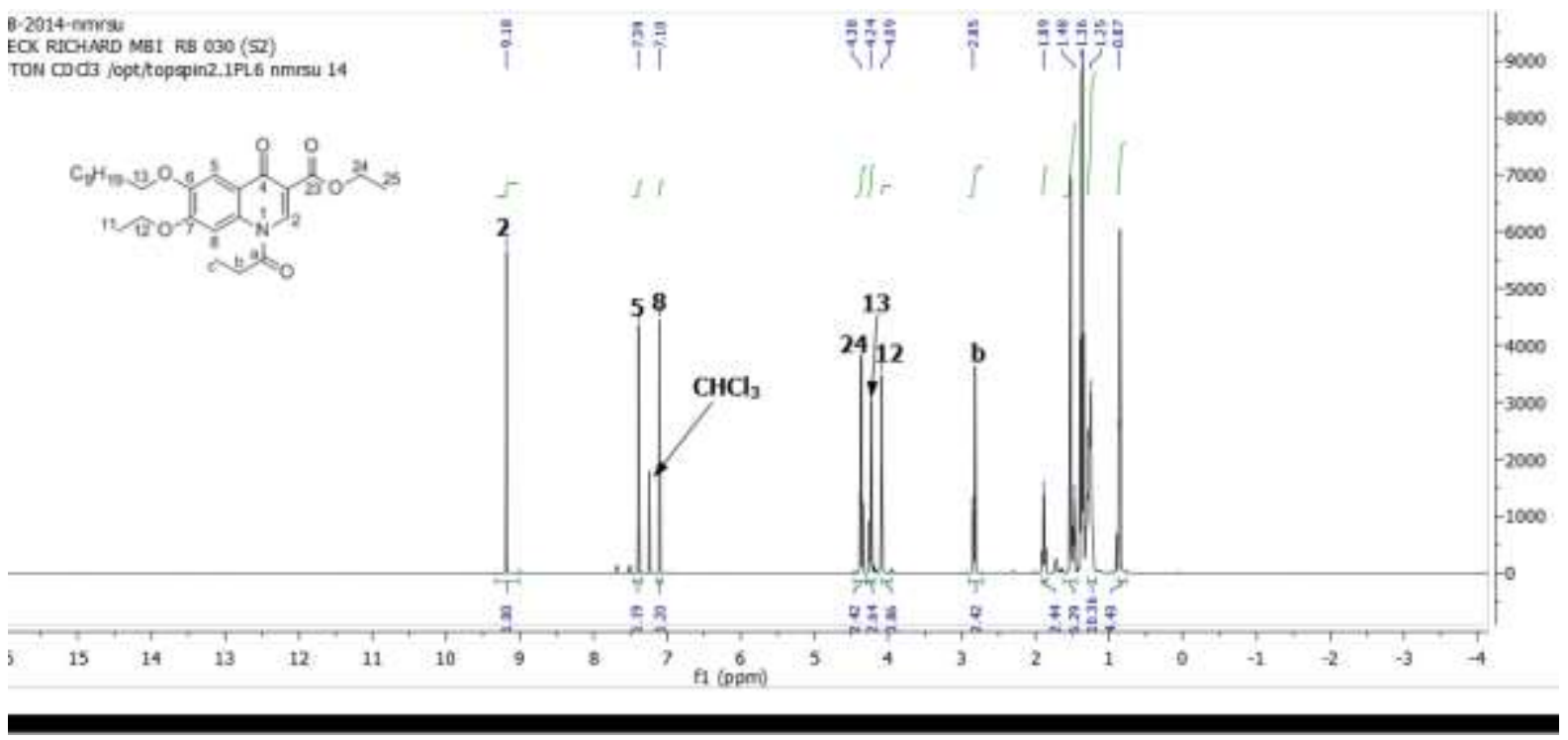




\section{${ }^{13} \mathrm{C}$ NMR spectrum}

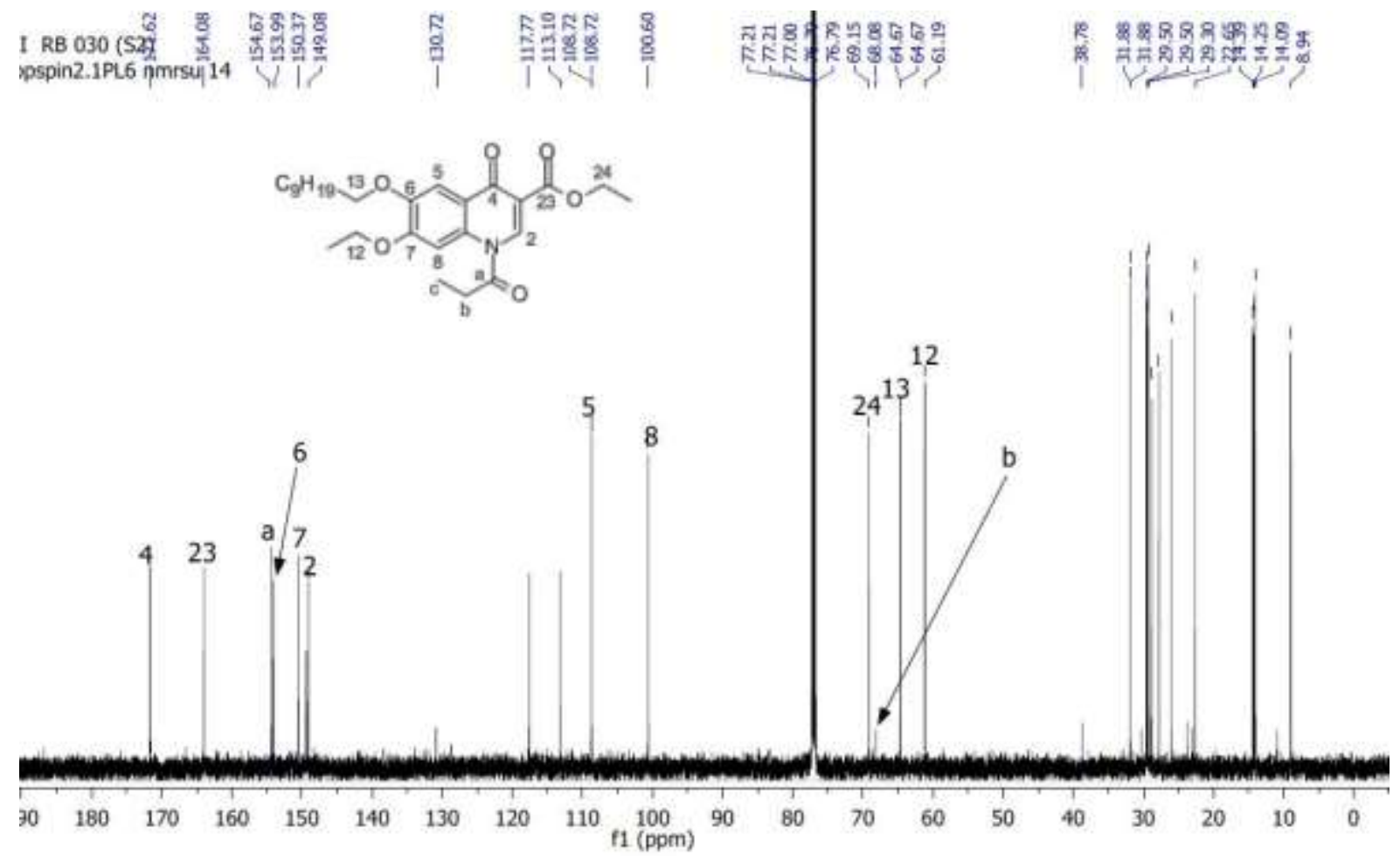

\section{HRMS spectrum}

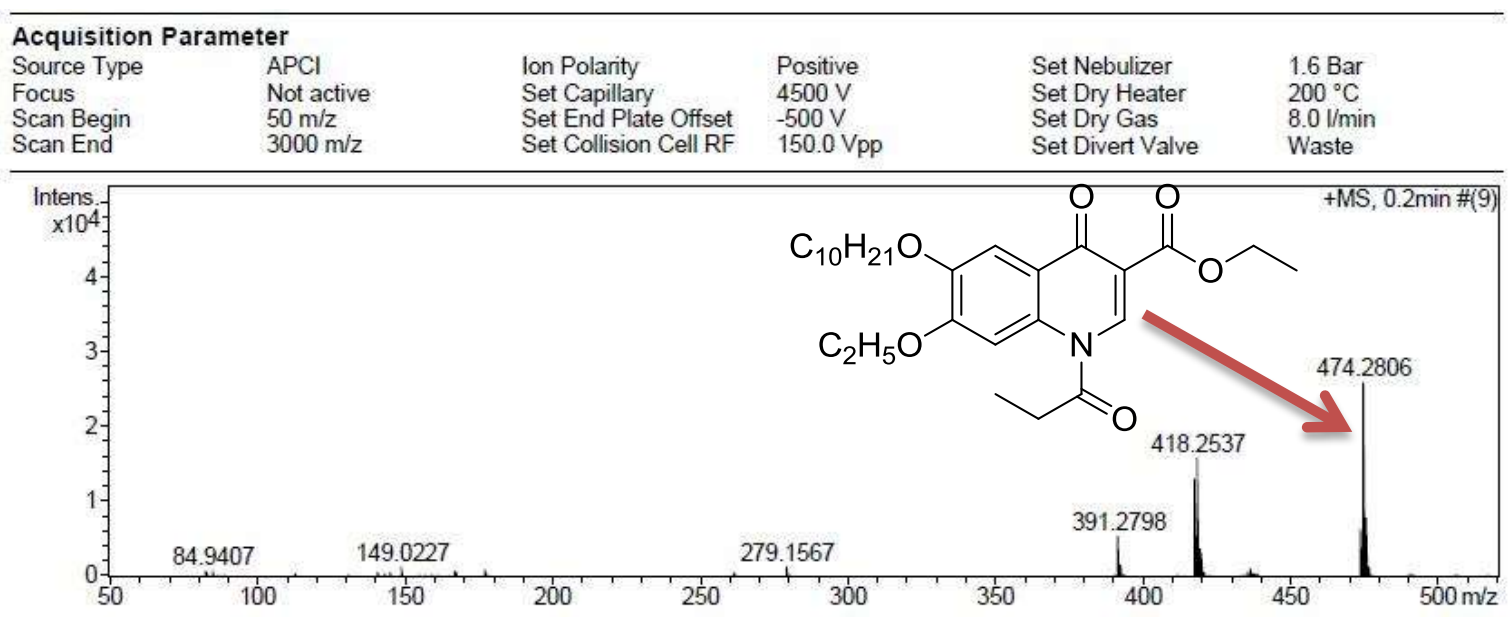




\section{Compound 33}

\section{${ }^{1}$ H NMR spectrum}

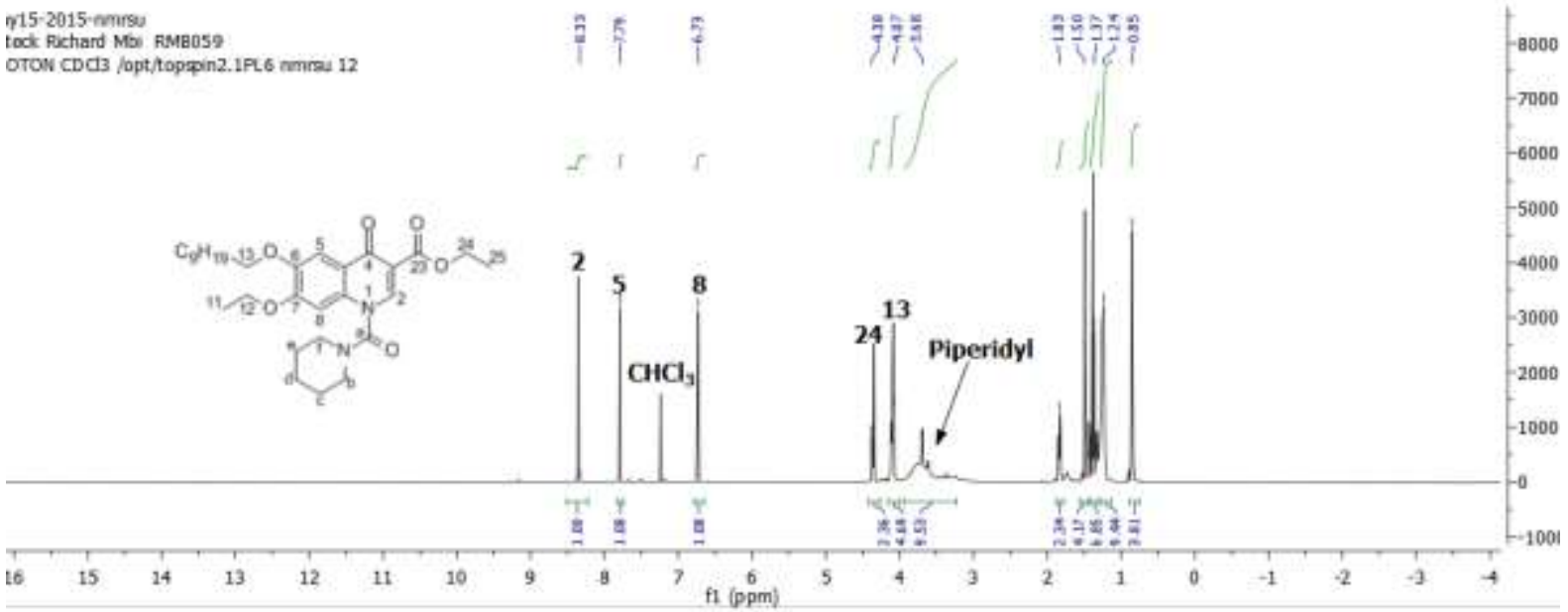

\section{${ }^{13}$ C NMR spectrum}

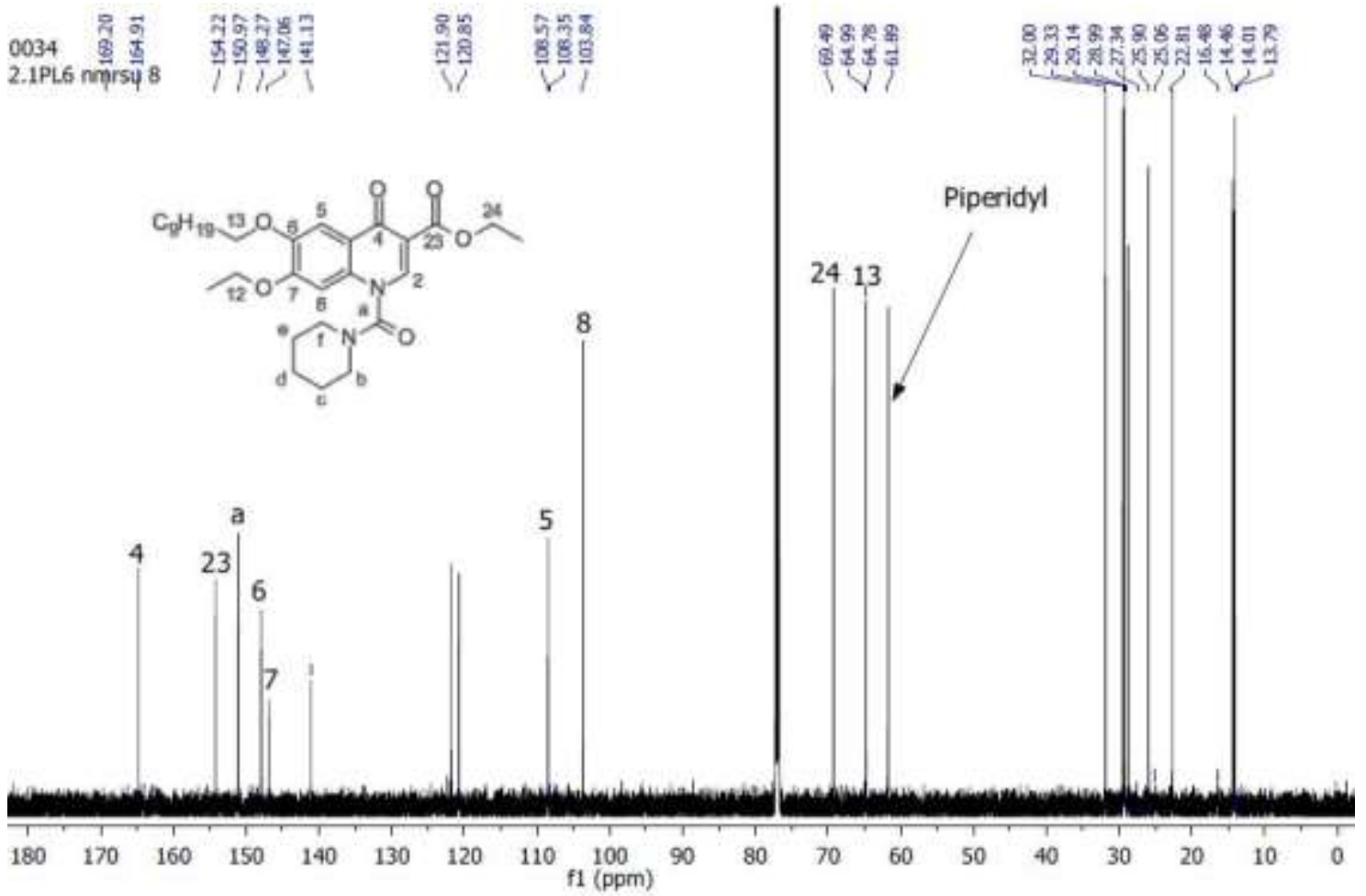


HRMS spectrum

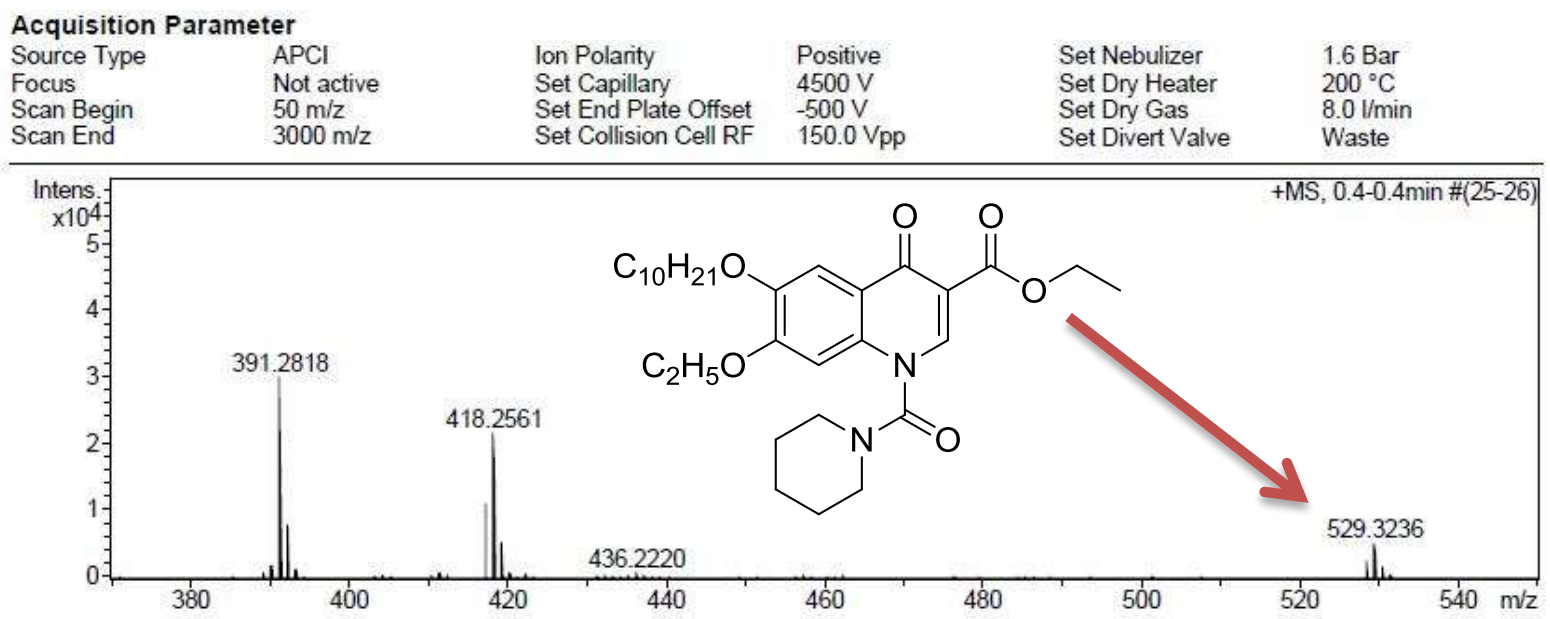

